\title{
Case Law versus Statute Law: An Evolutionary Comparison
}

\author{
Giacomo A. M. Ponzetto and Patricio A. Fernandez
}

\begin{abstract}
Case law develops gradually through the rulings of appellate judges who have heterogeneous preferences but are partially bound by stare decisis. We show that its evolution converges toward more efficient and predictable legal rules. Since statutes do not share this evolutionary property, case law is the best system when the efficient rule is time invariant, even if the legislature is more democratically representative than individual judges are. In the presence of social change, the ideal legal system includes both legislation and judicial decisions as complementary sources of law. Our model thus explains the modern history of common law and the observed cross-country correlation between legal origins and economic outcomes. It also predicts the gradual convergence of civil law and common law toward a mixed system.
\end{abstract}

\section{INTRODUCTION}

Modern legal systems are based on two primary sources of law: acts of legislation and judicial decisions. The comparative merits of these two lawmaking mechanisms have been debated since antiquity. Proponents of statute law such as Aristotle, Hobbes, and Bentham have stressed the certainty of precisely formulated general rules and the greater legitimacy of laws enacted by the sovereign authority and, in the modern era, by the democratic representatives of the people. In contrast, supporters of

gIACOMO A. M. PONZETTO is a doctoral candidate in economics at Harvard University. PATRICIO A. FERNANDEZ is a doctoral candidate in philosophy and economics at Harvard University. We are grateful to Alberto Alesina, John Coates, Alfred Galichon, Nicola Gennaioli, Edward Glaeser, Oliver Hart, Anthony Niblett, Eric Posner, Richard Posner, Holger Spamann, and particularly Louis Kaplow and Andrei Shleifer for helpful comments. Ponzetto acknowledges financial assistance from the Marco Fanno Foundation, the Mario Gasbarri Foundation, and the Institute for Humane Studies.

[Journal of Legal Studies, vol. 37 (June 2008)]

(C) 2008 by The University of Chicago. All rights reserved. 0047-2530/2008/3702-0011\$10.00 
case law such as Cato, Burke, and Hayek have highlighted the value of the evolving tradition embodied in the history of judicial precedents.

Despite the long-standing interest in this comparison, there is no consensus on a formal model for its analysis. This paper presents a simple framework that allows us to assess the efficiency properties of case law and statute law in a dynamic setting. We can thus derive implications on the respective roles of statutes and precedents in an optimal legal system. Our model provides empirical predictions on the evolution of a legal system over time as well as on the cross-sectional comparison of different legal systems.

In law and economics, the most prominent theory supporting judgemade law is the hypothesis of its efficiency advanced by Richard Posner ([1973] 2007), who argued essentially that common-law judges will agree on efficiency maximization as a shared aim. Cooter, Kornhauser, and Lane (1979) proved that case law improves over time when judges are welfare maximizers endowed with imperfect information, but Hadfield (1992) showed, conversely, the emergence of bias even with efficiency-seeking judges when the same rule has to be applied to heterogeneous cases. Priest (1977) and Rubin (1977) provided further theoretical support for the convergence hypothesis by grounding it in the fact that incentives to litigate, and eventually change, a prevailing legal rule are inversely related to its efficiency. However, Landes and Posner (1979) took the opposite view, arguing that it is, rather, more efficient rules that create greater incentives to litigate, since they induce the expectation of an efficient judgment.

More fundamental, an optimistic portrait of judges as efficiency maximizers is far from uncontroversial. In particular, the view that judges' self-interest and personal biases play a major role in determining judicial decisions was at the heart of the scholarly tradition of legal realism (Holmes 1897; Radin 1925; Frank 1930; Llewellyn 1930b). More recently, Zywicki (2003), albeit conceding that common-law courts may have aimed at efficiency in the nineteenth century, concludes that they can no longer do so, being too influenced by idiosyncratic preferences and direct pressure from litigants. A vast literature has all but proved that Supreme Court decisions are shaped by ideology at least as much as by precedent (George and Epstein 1992; Brenner and Spaeth 1995; Songer and Lindquist 1996; Segal and Spaeth 1996, 2002; McGuire and MacKuen 2005; Posner 2005b; Hansford and Spriggs 2006). ${ }^{1}$ Recent

1. Chief Justice Hughes was quoted as stating that, "[a]t the constitutional level where 
research has shown that this is not a unique feature of constitutional law but that individual tastes and ideologies affect rulings in ordinary appellate courts as well (Partridge and Eldridge 1974; Rowland and Carp 1996; Revesz 1997; Pinello 1999; Klein 2002; Sunstein, Schkade, and Ellman 2004).

Yet the attitudinal model of judicial decision making does not necessarily ring the death knell for Posner's convergence hypothesis. Cardozo (1921, p. 178) described case law as an evolutionary process in which the biases of successive judges offset each other: a process whereby "the bad will be rejected and cast off in the laboratory of the years," leading to legal outcomes that are more uniform and of greater value than are the individual judicial decisions considered in isolation. This alternative explanation of the benefits of legal evolution has been introduced in the law and economics literature by Gennaioli and Shleifer (2007). They analyze common law in the context of the attitudinal model: biased judges favor different types of litigants and can distinguish precedents at some personal cost. Distinguishing has a social cost because it allows judges to implement their idiosyncratic biases that distort the rule away from efficiency, but it also introduces new empirical dimensions into the law, thereby yielding a social benefit through increased precision of the legal rule. Considering this trade-off, Gennaioli and Shleifer conclude that legal evolution is on average beneficial, a result that they label the Cardozo Theorem.

Following the same attitudinal approach, we present a model of decision making by heterogeneous appellate judges who constantly innovate at the margin upon established precedents. These idiosyncratic innovations are not assumed to correspond to improvements in the informational content of the legal rule, but, as is consistent with Cardozo's intuition, they are shown to result in subsequent judges' biases balancing one another over time. We conclude that, as a consequence, case law is a continuous, never-ending process of evolution of legal rules that is characterized by probabilistic convergence toward greater efficiency and predictability, which supports Posner's hypothesis through the underlying mechanism described by Cardozo.

We also show that endogenous litigation whose intensity is positively correlated with the inefficiency of existing rules improves asymptotic efficiency but is not a requisite for convergence. The productive efficiency

we work, ninety percent of any decision is emotional. The rational part of us supplies the reasons for supporting our predilections" (Douglas 1980, p. 8). 
382 / THE JOURNAL OF LEGAL STUdies / VOLUME 37 (2) / JUNE 2008

of the court system in working through its caseload also contributes to the efficiency of the law. Finally, convergence is hindered, but never eliminated, if judicial decisions are strategically motivated, namely, if each judge not only decides on the basis of precedent and of the rule he or she considers most appropriate but also consciously introduces a further bias in an attempt to undo in advance the distinguishing that will be undertaken by his or her future colleagues. The resulting extremism and uncertainty may account for the popular aversion to judicial activism.

The importance of the convergence of judge-made law can be assessed in comparison to the alternative of statute law. Statutes have no intrinsic evolutionary property, and their quality simply reflects that of the electoral process. It is natural to think that the legislature is closer than the judiciary to the preferences of the public, because of its more direct democratic representativeness (Pound 1908; Scalia 1997). We confirm this intuition through a simple political economy model. Both legislators and judges are selected by an imperfectly democratic process that weighs disproportionately the preferences of special-interest groups. However, judges are additionally subject to pressure from parties appearing before their courts. While this implies a static advantage of legislation, in the long run the dynamic properties of judge-made law make it on average more efficient.

Leoni (1961) proposed a similar time-varying analysis of the certainty of the law. Statutes provide the short-run certainty of written law, but stare decisis endows case law with long-run certainty, because case law (unlike statutes) cannot change abruptly, and in the gradual process of distinguishing, countervailing judicial biases tend to cancel out. This hypothesis is borne out in our model, in which in the long run a system of judicial lawmaking almost surely attains more efficient rules than does legislation.

This conclusion of a stationary model seems to conflict with the ample evidence of the increasing use of statutes in common-law countries (Hayek 1973; Calabresi 1982; Glaeser and Shleifer 2003). We explain this phenomenon by extending our analysis to a setting that includes exogenous social change. Stare decisis can hinder the adaptation of legal rules to changed circumstances, and therefore it can become a burden for society. Thus, pure case law is optimal only in relatively static societies. For a more intense process of change, the optimum is a mixed system that includes legislation to deal with changing underlying conditions but integrates statutes into the body of case law and has courts 
interpret them in accordance with precedent. Our theoretical conclusion is reflected in the historical development of common law.

The optimal legal system is never pure statute law, even in the presence of continuous change in social conditions. Nonetheless, civil-law systems are characterized by their reliance on legislation instead of judgemade law. Thus, our model provides an explanation for the robust empirical finding that countries within the common-law tradition that originated in England outperform civil-law countries whose legal system originated from the continental European-and especially French-tradition in a number of financial, political, and socioeconomic indicators (La Porta et al. 1997, 1998, 1999, 2004; Mahoney 2001; Berkowitz, Pistor, and Richard 2003; La Porta, Lopez-de-Silanes, and Shleifer 2002; Beck, Demirgüç-Kunt, and Levine 2003a, 2003b, 2005; Mulligan and Shleifer 2005; Djankov, McLiesh, and Shleifer 2007; Djankov et al. 2008).

Moreover, we predict that social pressures to adopt more efficient institutions should lead to an increased role for case law in civil-law jurisdictions, just as they can explain the expansion of legislation in common law. Contemporary scholarship, indeed, suggests an ongoing convergence of the main legal families toward a mix of statute writing and judicial lawmaking (Glendon 1984; Zweigert and Kötz 1998; Glendon, Gordon, and Carozza 1999; Coffee 2002).

\section{THE EVOLUTION OF CASE LAW}

The law, or, more specifically, the rule governing a given legal issue, is represented by a point $x \in \mathbb{R}$. Every member $i$ of the population has individual preferences that are additively separable and depend on this legal rule according to single-peaked preferences. We specify a quadratic loss function $l_{i}(x)=\left(x-x_{i}\right)^{2}$; the bliss points $x_{i}$ are independent and identically distributed with continuous distribution $F$ on $\mathbb{R}$ with mean $x^{*}$ and variance $\sigma^{2}$.

Social welfare resulting from the law is then described by the aggregate loss function

$$
l(x)=\int_{-\infty}^{+\infty} l_{i}(x) d F\left(x_{i}\right)=\sigma^{2}+\left(x-x^{*}\right)^{2} .
$$

While the first term captures an intuitive effect-heterogeneity is costly since a single rule has to be adopted for all society-we take the variance 
of preferences in the population as exogenous and therefore normalize the aggregate loss function to $l(x)=\left(x-x^{*}\right)^{2}$, where $x^{*}$ characterizes the social optimum.

In a stochastic dynamic setting, the loss function takes the standard form of intertemporally separable expected utility. Hence, social welfare is described by the following:

$$
L(t)=E_{t}\left[\sum_{s=0}^{\infty} \beta^{s} l\left(x_{t+s}\right)\right]=\sum_{s=0}^{\infty} \beta^{s}\left[\left(E_{t}\left(x_{t+s}\right)-x^{*}\right)^{2}+\operatorname{Var}_{t}\left(x_{t+s}\right)\right]
$$

where $x_{t}$ is the law implemented in period $t$ and $\beta \in(0,1)$ is the social discount factor. This loss function captures two fundamental concerns of society: the tendency of legal rules to conform to the optimum every period and their ex ante predictability. In statistical terms, these are, respectively, the accuracy and the precision of the process; from the point of view of legal intuition, they capture the equity and the certainty of the law.

In a case law system, the rule evolves through the decisions of appellate courts. The fundamental source of law is precedent, by which previous decisions of the high court have normative value for subsequent adjudication. However, judges are not expected merely to apply a preexisting law to a particular case, but they must also create-or "discover," in the language preferred by Leoni (1961) and Hayek (1973)on their own the appropriate law, tailored to the case at hand.

As is consistent with the insights of legal realism and the findings of the political science literature, we adopt an attitudinal model, in which judicial decision making is driven by judges' attempts to shape legal rules in accordance with their individual preferences (Stone 1985; Posner 2005a; Gennaioli 2006). Judges are heterogeneous, and their individual preferences $\hat{x}^{J}$ have a distribution $\hat{F}_{\mathrm{J}}$ on $\mathbb{R}$, with mean $x^{*}$ and variance $\hat{\sigma}_{\mathrm{J}}^{2}$. This heterogeneity captures scholarly disagreement about different theories of justice, partisan ideology, the influence of rent-seeking litigants, lobbying, and conceivably bribing by special-interest groups. We show one possible microfoundation for this assumption through a simple special-interest model in Section 3.1.

We also follow Posner ([1973] 2007, 1990, 2005a) and Gennaioli and Shleifer (2007) in stressing the cost of legal innovation in terms of personal effort. A judge who abides by precedent can use information that has already been generated by previous cases and economize on new information gathering (Radin 1925; Llewellyn 1930a). A decision 
that drifts away from precedent requires harder work from the judge investigating the novel aspects of the case and the legal arguments connecting them to his or her ruling. ${ }^{2}$ The effort cost also reflects social norms concerning decisions in accordance with precedent. Judges who deviate from previous rulings are subject to more stringent professional criticism by their peers and to scrutiny by extrajudicial institutions and the general public: as a consequence, they are required to make a strong case for their distinguishing, which amounts to an exercise in legal scholarship. ${ }^{3}$ Stare decisis, instead, requires no more than the mention of relevant previous decisions, which has historically been less costly thanks to the availability of reliable law reports (Dawson 1968).

Finally, case law limits judges' authority to the adjudication of concrete disputes and does not accord them the power to promulgate abstract and general rules of broader scope. Hence, our baseline model considers judges whose exclusive concern is establishing the rule they consider most appropriate for adjudicating the specific case they are deciding. We interpret a conscious effort to influence strategically the future evolution of precedent as a manifestation of judicial activism, which we separately address in proposition 3 below.

In brief, case law, expressed as $x_{t}^{\mathrm{J}}$, is made by judges who weigh two competing claims: on the one hand, a desire to adjudicate a case according to their own attitudes toward justice and the litigants and, on the other, a preference for economizing on the effort required for legal innovation. This fundamental trade-off is captured by a simple utility function that is quadratic in deviations of the ruling both from the judge's bliss point and from established precedent:

$$
l_{\mathrm{J}}\left(\hat{x}_{t}^{\mathrm{J}}, x_{t}^{\mathrm{J}}, x_{t-1}^{\mathrm{J}}\right)=(1-\psi)\left(x_{t}^{\mathrm{J}}-\hat{x}_{t}^{\mathrm{J}}\right)^{2}+\psi\left(x_{t}^{\mathrm{J}}-x_{t-1}^{\mathrm{J}}\right)^{2},
$$

where $\psi \in[0,1]$ measures the cost of deviating from precedent. This parameter is meant to capture the degree to which the legal profession

2. This is especially apt in light of the attitudinal model. Radin (1925, p. 359) writes that judges first decide their favorite result and subsequently have the necessity of "working from their judgment backward, from a desirable conclusion to one or another of a stock of logical premises." This will be the easier the more beaten the path the judge is trying to trace from the case to a conclusion.

3. This informal social and professional scrutiny could be seen as the equivalent for appellate judges of the appeal process for lower courts. On the latter, Shavell (2006, p. 23) shows how the threat of appeal prevents large, arbitrary deviations by individual adjudicators; he also explicitly suggests that in order to police judicial behavior at the appellate level, "society . . . may induce appeals court judges to write opinions explaining their decisions." 
386 / THE JOURNAL OF LEGAL STUdies / VOLUME 37 (2) / JUNE 2008

considers the law to be malleable or conversely prizes its stability-a cultural boundary that Posner (1990, p. 100) calls "[t]he most important thing that law school imparts to its students."

This setup yields the following:

Proposition 1. Case law evolves according to the first-order linear autoregressive process

$$
x_{t+1}^{\mathrm{J}}=\psi x_{t}^{\mathrm{J}}+(1-\psi) \hat{x}_{t+1}^{\mathrm{J}}
$$

and therefore converges to the normal asymptotic distribution

$$
x^{\mathrm{J}} \sim N\left(x^{*}, \frac{1-\psi}{1+\psi} \hat{\sigma}_{\mathrm{J}}^{2}\right) .
$$

Given any current rule $x_{t}^{\mathrm{J}}$, the expected future rule $E\left(x_{t+s}^{\mathrm{J}} \mid x_{t}^{\mathrm{J}}\right)$ tends to the efficient rule $x^{*}$ with a factor of convergence $\psi$.

Each judge optimally solves his or her trade-off by marginally moving the rule inherited from the past in the direction of his or her own preferences. The evolution of case law therefore embodies formally Landes and Posner's (1979, p. 270) observation that "gradual or incremental change is the dominant form of change in a decentralized system of judge-made law [and] current decisions generate marginal and symmetric changes in precedents."

By the successive accretion of such innovations, case law at any point in time reflects to varying degrees the contributions of all past courts. The accumulation of judges' heterogeneous biases induces reversion to their average preference, which is the same as the bliss point of the average citizen, that is, the efficient rule $x^{*}$. In Cardozo's (1921, p. 177) famous words: "The eccentricities of judges balance one another [and] out of the attrition of diverse minds there is beaten something which has a constancy and uniformity and average value greater than its component elements."

Thus, case law is an evolving process that never settles on any immutable rule, efficient or otherwise. But it converges to an ergodic distribution that incorporates all different judicial points of view, each tending to smooth out the rough edges of another. Its asymptotic variance around the efficient solution is always smaller than the variance of judicial preferences themselves and can be arbitrarily small if each judge's ability to stamp his or her own views on the law is equally small. ${ }^{4}$

4. Formally, $\hat{\sigma}_{J}^{2}(1-\psi) /(1+\psi) \rightarrow 0$ when $\psi \rightarrow 1$. 
Proposition 1 thus supports Posner's hypothesis of the long-run efficiency of the common law.

It also highlights the trade-off inherent in the doctrine of stare decisis. A legal system with strict adherence to precedent (high $\psi$ ) will ultimately develop almost surely efficient rules, but its evolution toward the optimum will be very slow. Conversely, a system in which judges have more leeway in interpreting and overruling precedents (low $\psi$ ) has lower consistency and predictability even in the long run, but its convergence is more rapid.

These results can be visualized by a graph of the expected efficiency of case law as a function of the length of its evolution. The first judge, lacking any precedents to anchor a decision, will rule according to an idiosyncratic notion of equity, and the expected inefficiency of this ruling will exactly equal the heterogeneity of judicial preferences. Thereafter, although each realized decision need not be a step in the right direction, the evolution of precedent assures that, on average, case law will improve, and its expected inefficiency will decrease monotonically to the much lower asymptotic level. By plotting two different values of $\psi$, Figure 1 also conveys the trade-off between the speed of convergence and asymptotic efficiency. ${ }^{5}$

The evolution of judge-made law determines, on average, an increase not only in efficiency but also in social welfare, as we will discuss more extensively in the comparative analysis of Section 3. An analogous welfare result was first formally established by Gennaioli and Shleifer's (2007) Cardozo Theorem. But their modeling of case law is substantially different from ours, and the differences led them to a more restrictive view of the virtues of judicial lawmaking and to opposite conclusions about convergence.

Gennaioli and Shleifer (2007) present a two-period model that hinges on the existence of two predefined material dimensions of a series of analogous cases and, therefore, of the legal rule applying to them. They assume that the first judge to set a precedent can consider only one of the two dimensions. A second judge is absolutely bound by stare decisis on that dimension, but he or she may choose to introduce the second dimension into consideration: doing this involves a private cost of effort and a private benefit of bending the rule toward personal preferences.

In their model, the accretion of subsequent judges' idiosyncratic biases is not expected to improve the law: when averaged across all possible

5. The values plotted are $\psi=\{.64, .94\}$ with $\hat{\sigma}_{\mathrm{J}}^{2}=1$. 


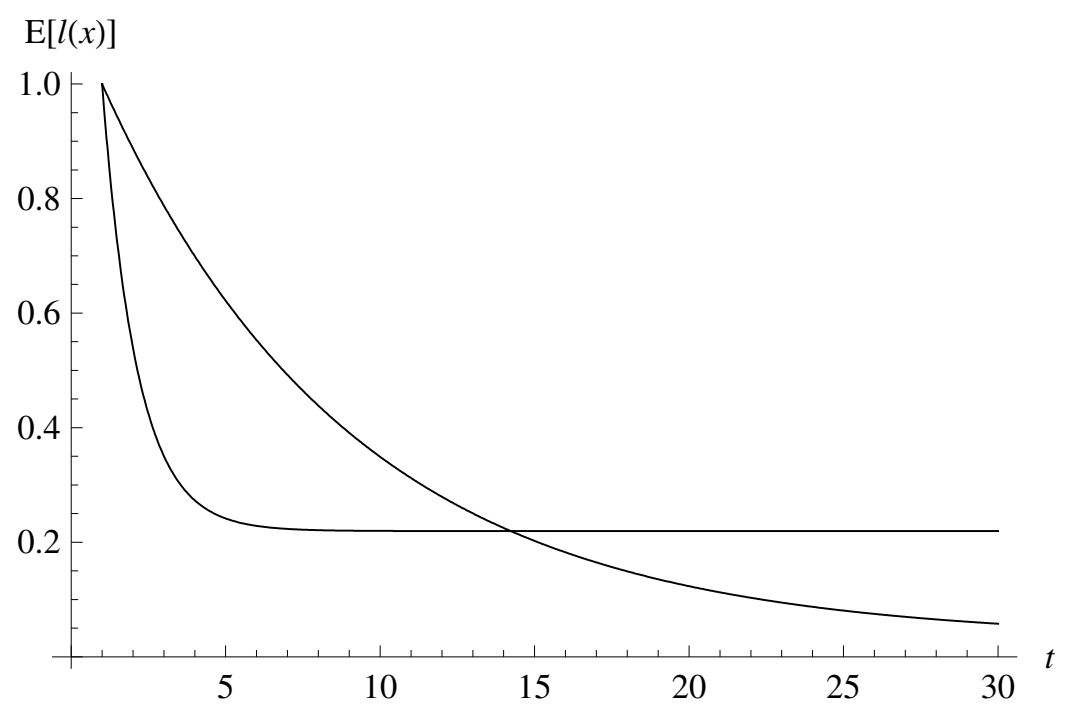

Figure 1. Ex ante expected loss from case law

paths of legal change, its effect is precisely nil. Distinguishing is socially beneficial only because judges are forced to introduce new material dimensions in order to introduce their own preferences into the law. Thus, the authors conclude that the diversity of judicial opinions is "the price to pay for judge-made law to adapt and become ever more precise" (Gennaioli and Shleifer 2007, p. 60).

Assuming a finite number of opportunities for distinguishing also implies that judge-made law reaches an immutable end state when the two material dimensions are exhausted. Gennaioli and Shleifer (2007, p. 59) assess the Posner hypothesis by considering the efficiency of this final rule and conclude that "a population of fully unbiased [efficiencymaximizing] judges is necessary for judge-made law to converge to the efficient two-dimensional rule." This condition is necessary but not sufficient and leads the authors to conclude that "the conditions for ultimate efficiency of judge-made law are implausibly stringent" (p. 62).

However, their emphasis on the informational content of distinguishing is reductive. Stone (1946, p. 189) argues that the distinction between material and immaterial dimensions is "a creative evaluation as opposed to a mechanical application" and that "[b]y looking at the facts it is impossible logically to say which are to be taken as the basis for the 
ratio decidendi" (p. 187). Like Stone (1946, 1964), Cardozo (1921, [1932] 1947), Llewellyn (1930a, 1960), and Posner (1990, 1996) emphasize that precedents are malleable and can be interpreted with ample leeway, their holdings read broadly or narrowly at the discretion of the later court. Thus, distinguishing may, but need not, be accompanied by an increase in the informational content of a rule. Nevertheless, the evolution of case law remains on average beneficial.

As is consistent with these insights of legal realism, our model rejects a stark dichotomy between some dimensions of a legal rule that are immutably fixed by precedent and others that can be shaped at will by a single judge. We consider instead that "following precedent is not an all-or-nothing choice between blind adherence and total disregard" (Hutchinson 2005, p. 147); departures from precedent, and the costly effort they require of a judge, are, rather, a matter of degree. As we have shown, this implies that legal evolution is intrinsically welfare enhancing because it brings a sequence of different-minded judges into an implicit interaction, leading them to offset each other's biases. Its benefits are present even when it does not make a legal rule factually more precise.

Moreover, our framework implies that the evolution of case law is a never-ending process of gradual change. This is consistent with a longstanding view of common law, which Cardozo (1921, p. 179) described as "ever in the making" and "an endless process of testing and retesting." Stone (1959, p. 620) went so far as to suggest that "the rule of stare decisis [compels] a self-perpetuating self-renewal of what the common law contains." This infinite-horizon framework implies that the appropriate notion of convergence is probabilistic (Cooter and Kornhauser 1980): it does not require that the perfectly efficient rule will apply forever but, in Priest's (1977, p. 65) words, that "the set of legal rules will always contain a greater proportion of efficient rules than judges themselves would prefer," even if all rules, including fully efficient ones, remain open to modification.

Thus, proposition 1 shows that Cardozo's own intuition of countervailing judicial biases supports Posner's hypothesis of the convergence of case law toward efficiency and thereby highlights the benefits of legal evolution.

\subsection{The Timing of Judicial Decisions and Endogenous Litigation}

Proposition 1 also identifies a trade-off between the eventual efficiency of case law and the speed of its convergence. The timing of the model 
depends on the occurrence of precedent-setting judicial decisions, and it remains to link such rulings to an objective calendar time.

The primary constraint is essentially technological. In most countries, courts of law operate at maximum capacity and nonetheless cannot fully satisfy the demand. The number of cases decided is a function of the number of judges and their efficiency in rapidly rendering a judgment. Thus, the fundamental atom of time in our model is the period it takes the court to process a case. This creates a natural parallel between the two notions of efficiency: if the legal system can process a greater number of cases, the evolution of case law is faster and the trade-off between speed and eventual optimality is relaxed. ${ }^{6}$

Equating each case with an opportunity to establish precedent is appropriate, at most, for single-bench supreme courts such as the U.S. Supreme Court or the House of Lords, while the focus of our analysis is on ordinary appellate courts that in practice process several thousands of cases a year. The crucial consideration is that most cases decided by an appellate court are purely factual and break no new legal ground; that is, they offer no rationale for setting a new precedent. We capture this phenomenon by assuming that there is a probability $p$ that any case is nontrivial, which enables the court to contribute to jurisprudential evolution. Such a setup introduces some analytical complication and an added source of uncertainty in the evolution of the law, namely, uncertainty in the timing of relevant precedents. However, it does not alter our conclusions. Proposition 1 can be restated as the following:

Corollary 1. If in every period the high court has probability $p \in$ $(0,1]$ of being able to refine the existing law, case law evolves according to the Markov process

$$
x_{t+1}^{\mathrm{J}}= \begin{cases}x_{t}^{\mathrm{J}} & \text { with } \operatorname{Pr} 1-p \\ \psi x_{t}^{\mathrm{J}}+(1-\psi) x_{t+1}^{\mathrm{J}} & \text { with } \operatorname{Pr} p\end{cases}
$$

and therefore converges to the asymptotic distribution

$$
x^{\mathrm{J}} \sim N\left(x^{*}, \frac{1-\psi}{1+\psi} \hat{\sigma}_{\mathrm{J}}^{2}\right) .
$$

Given any current rule $x_{t}^{\mathrm{J}}$, the expected future rule $E\left(x_{t+s}^{\mathrm{J}} \mid x_{t}^{\mathrm{J}}\right)$ tends to the efficient rule $x^{*}$ with a factor of convergence $1-p+p \psi$.

6. Djankov et al. (2003) show that the quality of courts, measured as the estimated duration of dispute resolution, is highly negatively correlated with procedural formalism but does not respond to the incentives that individual judges face. 
This corollary illustrates that our stylized assumption of a deterministic timing of precedent-setting decisions is equivalent to a more detailed stochastic formulation with a constant hazard rate. The only difference is that evolution is slower, because with probability $1-p$ a time period does not correspond to a change in the rule.

A more significant extension is the inclusion of a demand-side influence on the timing of precedent-setting rulings. Priest (1977), Rubin (1977), and Goodman (1978) proposed that the evolution of case law toward efficiency is driven by endogenous litigation: inefficient rules are more likely to be litigated and, as a consequence, to be subsequently improved. To capture formally this hypothesis, we assume that the probability that the court has a chance to refine the law at time $t$ is an increasing function $p($.$) of the distance between the existing rule x_{t-1}^{\mathrm{J}}$ and the social optimum $x^{*}$. For this state-contingent process, the transition path is no longer explicitly computable, but convergence still occurs, and we characterize the asymptotic distribution when judges' preferences are normal.

Proposition 2. Suppose that in every period the high court has an opportunity to refine the existing law $x_{t-1}^{\mathrm{J}}$ with probability $p\left(\mid x_{t-1}^{\mathrm{J}}-\right.$ $\left.x^{*} \mid\right) \in(0,1)$ such that $p^{\prime}>0$ for all $x_{t-1}^{\mathrm{J}} \in \mathbb{R}$. Suppose, moreover, that judges' preferences are normally distributed with mean $x^{*}$ and variance $\hat{\sigma}_{\mathrm{J}}^{2}$.

Then the asymptotic case law has expectation $E\left(x^{\mathrm{J}}\right)=x^{*}$ and variance

$$
\operatorname{Var}\left(x^{\mathrm{J}}\right)<\frac{1-\psi}{1+\psi} \hat{\sigma}^{2}
$$

This proposition provides formal support to the intuition that a positive responsiveness of caseload to the suboptimality of the current rule pushes toward greater asymptotic efficiency of case law. It represents a refinement of Cooter and Kornhauser's (1980) convergence result for the evolution of precedent in a discrete state space.

A potential trade-off derives again from the speed of convergence; however, this framework allows for some slackness of the constraint. Since faster jurisprudential evolution is always desirable ex ante, a higher average probability of legal innovation is certainly preferable. But for any average probability smaller than one, the system is asymptotically more efficient if the probability is decreasing as the law approaches the 
optimum. This makes the speed of convergence nonconstant, but it need not have an expected cost ex ante.

This mechanism, therefore, could be a further element driving case law toward efficiency. It is not, however, a necessary element: convergence still obtains under Landes and Posner's (1979) opposite hypothesis that litigation of efficient rules is more likely, although endogeneity of this sign increases the asymptotic variance.

\subsection{Strategic Behavior and Judicial Activism}

Proposition 1 assumes that each judge is purely focused on his or her own decision. This does not mean that judges ignore that general legal principles are derived from the solution of individual cases: we model them as setting precisely these underlying general rules. The operative restriction lies in the absence of a forward-looking strategic motivation: appellate judges, whose rulings constitute binding precedents, were assumed not to take into account, when deciding cases, that the subsequent evolution of the law results from the interaction between their own decisions and those of their future colleagues.

Yet judges may surely be mindful that the precedents they are setting will be distinguished and modified, and this awareness will lead them to change their rulings. In our framework, this strategic motive is introduced whenever judges are assumed to care explicitly about the future evolution of the law and not only about the case they are deciding. The infinite-horizon game between subsequent judges has an intuitive equilibrium that extends the results of proposition 1 above.

Proposition 3. Suppose that judges are concerned about the influence of their decisions on the future evolution of the law, and their subjective discount factor is $\beta_{\mathrm{J}} \in[0,1]$.

There exists an equilibrium of the judges' game such that case law evolves according to the first-order linear autoregressive process

$$
x_{t+1}^{\mathrm{J}}=a x_{t}^{\mathrm{J}}+(1-a) \hat{x}_{t+1}^{\mathrm{J}}+\frac{\beta_{\mathrm{J}} a(1-a)^{2}}{1-\beta_{\mathrm{J}} a}\left(\hat{x}_{t+1}^{\mathrm{J}}-x^{*}\right),
$$

which converges to the normal asymptotic distribution

$$
x^{\mathrm{J}} \sim N\left(x^{*}, \frac{1-a}{1+a}\left(\frac{1-\beta_{\mathrm{J}} a^{2}}{1-\beta_{\mathrm{J}} a}\right)^{2} \hat{\sigma}_{\mathrm{J}}^{2}\right) .
$$

Given any current rule $x_{t}^{\mathrm{J}}$, the expected future rule $E\left(x_{t+s}^{\mathrm{J}} \mid x_{t}^{\mathrm{J}}\right)$ tends to the efficient rule $x^{*}$ with a factor of convergence $a \in(0,1)$. 
The factor of convergence is a function of judges' incentives- $a(\psi$, $\beta_{\mathrm{J}}$ ) —such that case law is more stable when the effort required to change it is greater $(\partial a / \partial \psi>0)$ and judges are less forward looking $\left(\partial a / \partial \beta_{\mathrm{J}}<0\right)$.

The certainty of case law over any horizon is greater when judges are less forward looking $\left(\partial \operatorname{Var}\left(x_{t+s}^{\mathrm{J}} \mid x_{t}^{\mathrm{J}}\right) / \partial \beta_{\mathrm{J}}>0\right.$ for any $\left.s\right)$.

The standard model of proposition 1 is obtained in the limit as $\beta_{\mathrm{J}}=0$, which implies that $a=\psi$. More generally, the intuition behind the determinants of the persistency of precedent $(a)$ is straightforward. The more forward looking a judge is (the higher the $\beta_{\mathrm{J}}$ ), the more willing he or she is to make the effort to deviate from precedent, since the judge anticipates that the ruling will not only decide the case at hand but also marginally affect the future evolution of case law. In contrast, the higher the cost of deviating from stare decisis, the smaller such deviations will be. At one extreme, $\psi=0$ implies that $a=0$, since every judge independently and arbitrarily decides the case at hand on the basis of personal preferences. At the opposite extreme, $\psi \rightarrow 1$ implies that $a \rightarrow 1$ regardless of $\beta_{\mathrm{J}}$, because deviations from precedent are infinitely costly. This confirms our previous result that the asymptotic variance of case law can be reduced arbitrarily, albeit at the expense of the speed of convergence $\left(\lim _{\psi \rightarrow 1} \operatorname{Var}\left(x^{\mathrm{J}}\right)=\lim _{a \rightarrow 1} \operatorname{Var}\left(x^{\mathrm{J}}\right)=0\right)$.

While intuitively clear, the change in the factor of convergence $a$ is not the main effect captured by proposition 3; quantitatively, $a$ always remains close to $\psi .^{7}$ The most important implication of judges' explicit concern for the evolution of future law $\left(\beta_{\mathrm{J}}>0\right)$ is instead the introduction of a strategic element in their decision process. Since each judge expects future rulings on average to revert toward the mean, he or she is led to be more extreme in order to have a longer-lasting impact on the law. This strategic extremism induces the socially damaging increase in legal uncertainty.

We interpret this phenomenon as a feature of what is popularly called judicial activism and, indeed, as an explanation of the negative connotation that this rather broad and vague concept has in political debate: "The word 'activist' is rarely defined. Often it simply means that the judge makes decisions with which the critic disagrees" (Gewirtz and Golder 2005, p. A19). Admittedly, some scholarly definitions equate judicial activism with the mere fact that judges have an active lawmaking role (for example, Malleson 1999). However, such a definition is so

7. Precisely, $\min \{a / \psi\}=23 / 27 \approx .85$. 
broad that it becomes pointless when applied to a case law system. Not only is it necessary for common-law judges to be continually refining the law, but this very fact determines convergence toward efficiency. If this were judicial activism, we could not agree with its usage as a term of opprobrium. ${ }^{8}$

Instead, the forward-looking strategic motive $\left(\beta_{\mathrm{J}}>0\right)$ both makes judges bolder in departing from precedent $(\alpha<\psi)$ and, most importantly, induces all but perfectly efficiency oriented judges $\left(\hat{x}^{J} \neq x^{*}\right)$ to issue more extreme rulings. This implies a detrimental increase in the variance of judgments and more pronounced observed judicial partisanship, which reduces the certainty of case law and its asymptotic efficiency. Therefore, this interpretation of judicial activism accounts for the unvarying pejorative connotation of the phrase, as well as for the popular perception that activism is intrinsically connected to a judge's partisan ideology or legal philosophy.

\section{STATUTE LAW AS AN ALTERNATIVE}

Whereas judge-made law is bound by the principle of stare decisis, statutes do not have to pay homage to precedent and, indeed, can have the precise intent of breaking away from preexisting rules (Hayek 1973). Formally, the legislature has the authority to change the law at will.

In practice, this authority is limited, not unlike a judge's power, by a cost of effort. But the choice facing legislators is fundamentally different from the one facing a judge constrained by precedent. The latter must render a judgment, so the effort choice concerns only the degree of creativity he or she wishes to introduce in his or her opinion. On the contrary, the choice of the legislature is between inaction and statute writing. Once the decision to introduce a new statute is made, its content is evaluated on its own, and not by comparison to precedents. This can be parsimoniously captured by a fixed cost of legislation, $\Delta \geq 0$, which reflects the need to activate the bureaucratic machinery of statute writing

8. An analogous point has been made by Posner (1996), whose definition of judicial activism relates instead to the separation of powers. This definition aligns with popular commentary of Supreme Court activity, but it cannot account for the unmitigated negativity associated with the term. Posner (1996, p. 211) himself argues that "judicial self-restraint [the opposite of activism in his terminology] is a contingent, a time-and-place-bound, rather than an absolute good." In this spirit, we also show in proposition 7 that a limited degree of creative interpretation of statutory provisions by judges is always desirable. 
as well as transaction costs involved in bargaining between different political actors. ${ }^{9}$

The legal rule preferred by a legislature is not determined directly as the bliss point of any individual but is the outcome of a political process involving a multiplicity of different agents. Capturing the imperfections of any real-world polity, we represent this outcome by the variable $\hat{x}^{\mathrm{L}}$ with distribution $\hat{F}_{\mathrm{L}}$ having continuous density $\hat{f}_{\mathrm{L}}$ on $\mathbb{R}$, mean $x^{*}$, and variance $\hat{\sigma}_{\mathrm{L}}^{2}$. Section 3.1 presents a model motivating this assumption. For the sake of brevity, we will refer to $\hat{x}^{\mathrm{L}}$ as the preference of the legislature.

Therefore, we can represent the decision problem of the legislature by the loss function

$$
l_{\mathrm{L}}\left(\hat{x}_{t}^{\mathrm{L}}, x_{t}^{\mathrm{L}}, x_{t-1}^{\mathrm{L}}\right)=\left(x_{t}^{\mathrm{L}}-\hat{x}_{t}^{\mathrm{L}}\right)^{2}+\Delta \chi\left(x_{t}^{\mathrm{L}} \neq x_{t-1}^{\mathrm{L}}\right),
$$

where $\chi$ denotes the characteristic or indicator function and $x_{t}^{\mathrm{L}}$ is the legal rule provided by statutes for period $t$.

This yields the following:

Proposition 4. Statute law evolves according to a strictly stationary Markov process whose asymptotic distribution $x$ coincides with the distribution of legislative preferences $\hat{x}^{\mathrm{L}}$. This is also the unconditional distribution of statute law at any time $\left(x_{t}^{\mathrm{L}} \sim \hat{x}^{\mathrm{L}}\right.$ for all $\left.t\right)$.

Since the cost of statute writing is fixed and does not depend on the distance between the new rule and the old rule, the legislature faces a binary choice between inaction, which preserves the preexisting statute, and the promulgation of a new statute that embodies the current legislature's own preferences.

Thus, at any time statute law coincides with the preferences of the single legislature that was sitting when the last statute was enacted. Since we do not consider structural changes in the political process over time, this means that ex ante statutes always have the invariant distribution of legislative preferences $\hat{x}^{\mathrm{L}}$. The mechanism of sequential interaction between successive lawmakers that characterizes case law is absent, and therefore it is no surprise that so is long-run convergence.

In fact, the long-run properties of statute law are independent of $\Delta$. In the short run, a cost $\Delta>0$ of statute writing is a source of inertia in

9. We could imagine that the status quo constitutes a reference point for intraparliamentary bargaining. The existence of a threat point has distributional consequences, but it does not affect the policy choice if other mechanisms, such as pork-barrel spending, are available to achieve utility transfers between politicians. 
statute law. However, this inertia prevents a statute from being replaced by either a better or worse new rule. Depending on the specific current state of the law and on the distribution of preferences $\hat{F}_{\mathrm{L}}$, either effect may dominate at any point in time. On average the two effects are perfectly offsetting: the ex ante distribution of $x_{t}$ is independent of $\Delta$.

\subsection{The Legislature and the Judiciary in a Democracy}

Legislation has traditionally been interpreted as a sovereign act of the legitimate political authority. This conception, dating back to the rise of absolute monarchy (Hobbes [1681] 2005), became part of the common heritage of the Enlightenment and received its modern normative grounding from the establishment of democratic institutions. When sovereignty was vested in an absolute monarch, it could be argued that the public needed protection from its arbitrary exercise. On the contrary, in a democracy the mechanisms of legislative representation ensure that statutes tend to reflect the preferences of the public itself. Thus, Pound (1908, p. 406) argued that in comparison to judicial decisions, "[w]e recognize that legislation is the more truly democratic form of lawmaking. We see in legislation the more direct and accurate expression of the general will."

Naturally, a perfect polity would have a legislature whose preferences infallibly coincide with the social optimum $\left(\hat{\sigma}_{\mathrm{L}}^{2}=0\right)$, but this utopian limit case is contradicted both by empirical evidence and by common sense. At the same time, as is consistent with Pound's (1908) argument, the representativeness of the legislature provides more uniformity than do the idiosyncratic preferences of heterogeneous judges, which is captured formally by $\hat{\sigma}_{\mathrm{L}}^{2}<\hat{\sigma}_{\mathrm{J}}^{2}$. These bounds on the variance of legislative preferences can be explained by a simple model that takes into account the role of special-interest groups in policy determination (Grossman and Helpman 2001).

In particular, $S>0$ special-interest groups are exogenously formed from the general population, each having the preferences $\hat{x}_{s}$ of a random citizen (independently and identically distributed with mean $x^{*}$ and variance $\left.\sigma^{2}\right)$. Democratic politics have a degree of imperfection, $\iota \in(0,1)$, such that the social optimum carries a weight of only $(1-\imath)$ in legislative preferences, while the idiosyncratic preferences of special-interest groups have an aggregate weight $\iota$ :

$$
\hat{x}^{\mathrm{L}}=(1-\imath) x^{*}+\iota \sum_{s=1}^{S} \frac{\hat{x}_{s}}{S} .
$$


Two standard explanations for $\iota>0$ can be given. Following Grossman and Helpman (1994), we could assume that the special-interest groups form lobbies that influence policy by providing contributions to elected officials. Following Glaeser, Ponzetto, and Shapiro (2005), we could offer an alternative interpretation that focuses purely on electoral competition. If members of the special-interest groups acquire better information concerning the platform choices of political parties than does the general population, then politicians will cater to the preferences of these groups in order to maximize their support at the polls.

Judges have a priori the same preference structure as the legislature, being either directly elected by the same voters or appointed by the representatives themselves. However, they are also influenced by a specialinterest group that is directly involved in the case before their court, as in Glaeser and Shleifer (2002). Hence, their preferences are

$$
\hat{x}^{\mathrm{J}}=(1-b) \hat{x}^{\mathrm{L}}+b \hat{x}_{s},
$$

where $b \in(0,1)$ measures outside influence on judicial decisions: this can result simply from the greater resources available to more powerful litigants-from better lawyers to amicus curiae briefs-or conceivably even from outright intimidation and bribing.

This setup yields the following:

Proposition 5. If both the legislature and the judiciary are democratically selected by a political process with a degree $\iota \in(0,1)$ of imperfection, and judges are subject to a degree $b \in(0,1)$ of influence from special-interest groups, then we have the following:

1. Legislative preferences $\hat{x}^{\mathrm{L}}$ have a mean $x^{*}$ and have a positive variance $\hat{\sigma}_{\mathrm{L}}^{2}(\iota)$ that is smaller than the variance of preferences in the population $\left(\hat{\sigma}_{\mathrm{L}}^{2} \in\left(0, \sigma^{2}\right)\right)$ and increasing in political imperfection $\left(\partial \hat{\sigma}_{\mathrm{L}}^{2} / \partial \iota>0\right)$.

2. Judges' preferences $\hat{x}^{J}$ have a mean $x^{*}$ and have a positive variance $\hat{\sigma}_{\mathrm{J}}^{2}(\iota, b)$ that is smaller than the variance of preferences in the population but is greater than the variance of legislative preferences $\left(\hat{\sigma}_{\mathrm{J}}^{2} \in\left(\hat{\sigma}_{\mathrm{L}}^{2}, \sigma^{2}\right)\right)$ and increasing both in political imperfection $\left(\partial \hat{\sigma}_{\mathrm{J}}^{2} / \partial \iota>0\right)$ and in the outside influence on judicial decisions $\left(\partial \hat{\sigma}_{\mathrm{J}}^{2} / \partial b>0\right)$.

3. The relative democratic representativeness of the judiciary compared to the legislature $\left(\hat{\sigma}_{\mathrm{L}}^{2} / \hat{\sigma}_{\mathrm{J}}^{2} \in(0,1)\right)$ increases with political imperfection $\left(\partial\left(\hat{\sigma}_{\mathrm{L}}^{2} / \hat{\sigma}_{\mathrm{J}}^{2}\right) / \partial \iota>0\right)$ and decreases with outside influence on judicial decisions $\left(\partial\left(\hat{\sigma}_{\mathrm{L}}^{2} / \hat{\sigma}_{\mathrm{J}}^{2}\right) / \partial b<0\right)$.

Both judges and the legislature have induced preferences that reflect 
398 / THE JOURNAL OF LEGAL STUdies / VOLUME 37 (2) / JUNE 2008

those of the whole population but with unequal weighting resulting from the disproportionate power of special-interest groups. Since lobbies represent the interests of randomly drawn citizens, there is no average bias in either judicial or legislative preferences. However, a heterogeneous influence implies that these preferences are themselves heterogeneous and deviate from the social optimum.

The greater heterogeneity of judges' preferences captures one disadvantage of creating the law from decisions about particular cases rather than from general, abstract rules. When all branches of government are democratically elected, all suffer from the inevitable imperfections of the democratic process. But judges are subject to additional pressure from the groups that are affected directly from their judgments, rather than merely by the general principle those judgments will help develop. As a consequence, their opinions are more variable than is legislation, because they depend not only on the society-wide balance of general and special interests but also on the varying power of the parties appearing before them in court.

Naturally, greater insulation of judges from the pressure of powerful litigants (lower $b$ ) improves judicial decision making but does not affect legislation. A lower influence of special-interest groups in the democratic process (lower $\iota$ ) instead improves the operation of both branches. However, it makes any remaining judicial bias $b$ relatively starker, thereby enhancing the relative representativeness of the legislature.

\subsection{The Benefits of Evolution}

Propositions 1 and 4 have established that case law is endowed with a tendency to converge toward greater efficiency, which statute law does not share. This captures the main argument proposed by supporters of judicial lawmaking well before Cardozo (1921). In particular, Burke ([1790] 1999, p. 191) praised "the science of jurisprudence, the pride of the human intellect, which, with all its defects, redundancies, and errors, is the collected reason of ages, combining the principles of original justice with the infinite variety of human concerns."

In contrast, proposition 5 has given a formal representation of the equally old and widespread idea that lawmaking power should be vested in the legislature rather than the judiciary, owing to the closeness of the former to the will of the people.

Another traditional argument in favor of statutes has been that they provide greater certainty of the law than do judicial precedents. Bentham (1998, p. 102) went so far in criticizing case law as to claim that "un- 
certainty is the inherent disease of that wretched substitute to law, which is called unwritten law, and which, in plain truth, is not law at all."

The predictability of legal rules is such a paramount social concern that Holmes $(1897$, p. 458) defined law itself as "nothing but a prediction." Within our mathematical model, the desire for certainty is captured by the convexity of the loss function, which directly implies risk aversion over future legal rules.

Written law precisely defines ex ante the rule that shall be applied to any controversy. At least in principle, every individual can exactly foresee the immediate legal consequences of his or her actions. Formally, the rule $x_{t}^{\mathrm{L}}$ is known at $t$. Instead, established precedents are only the starting point for the evolution of case law, so individuals remain partly uncertain of the ruling that would be issued if their cases were brought to court. Formally, only $x_{t-1}^{\mathrm{J}}$ is known at $t$, and $x_{t}^{\mathrm{J}} \mid x_{t-1}^{\mathrm{J}}$ is a random variable that will be realized ex post when a judgment is rendered. ${ }^{10}$

However, we should not focus exclusively on the predictability of the legal rule applying to the present: for a broad range of economic decisions, what is essential is the persistence of a stable legal framework over time. As Leoni (1961, p. 85) remarked, the predictability of the law given by written statutes is only short-run certainty, while long-run certainty requires the law "never to be subjected to sudden and unpredictable changes," a property that characterizes instead judge-made law, as is shown in proposition 1.

In fact, not only the predictability of the two lawmaking mechanisms, but also their efficiency, is best understood in terms of the dichotomy between a short-run and a long-run horizon. Formally, we can prove the following:

Corollary 2. Provided that the institutional importance of precedent is sufficiently high, that is, $\psi \in\left(\left(\hat{\sigma}_{J}^{2}-\hat{\sigma}_{\mathrm{L}}^{2}\right) /\left(\hat{\sigma}_{\mathrm{J}}^{2}+\hat{\sigma}_{\mathrm{L}}^{2}\right), 1\right)$, we obtain the following:

1. Conditional on the information available in any period $t$, the legal rule that will apply to the same period is more predictable under statute law than under case law $\left(0=\operatorname{Var}\left(x_{t}^{\mathrm{L}} \mid x_{t}^{\mathrm{L}}\right)<\operatorname{Var}\left(x_{t}^{\mathrm{J}} \mid x_{t-1}^{\mathrm{J}}\right)\right)$, but the legal rule

10. The difference between case law and statutes shares some features with that between standards and precise rules. Kaplow's $(1992,2000)$ comparative analysis highlights that standards whose precise content is given ex post are more costly to predict for the agents and their legal advisors than are rules whose detailed application is determined ex ante. 


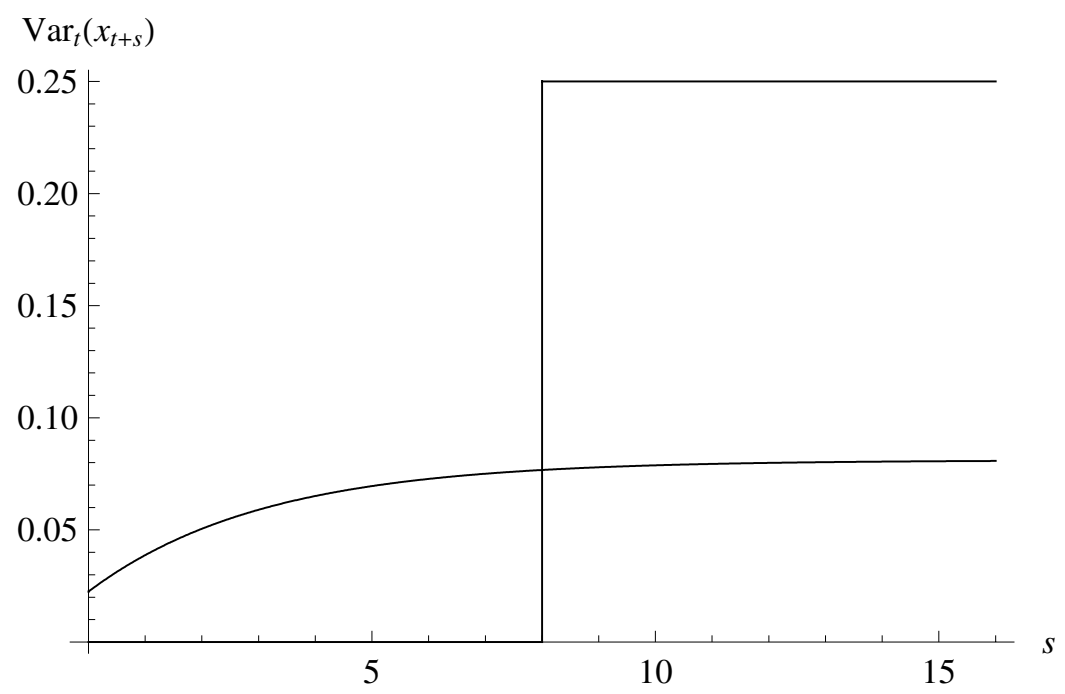

Figure 2. Uncertainty of statutes and case law

that will apply in the long run is more predictable under case law than under statute law $\left(\lim _{s \rightarrow \infty} \operatorname{Var}\left(x_{t+s}^{\mathrm{L}} \mid x_{t}^{\mathrm{L}}\right)>\lim _{s \rightarrow \infty} \operatorname{Var}\left(x_{t+s}^{\mathrm{J}} \mid x_{t-1}^{\mathrm{J}}\right)\right)$.

2. There exists a finite value $T$ such that expected efficiency of statute law is lower than that of case law if, and only if, the latter embodies at least $T$ precedents $\left(E\left[l\left(x_{t}^{\mathrm{L}}\right)\right] \geq E\left[l\left(x_{t}^{\mathrm{J}}\right)\right] \Leftrightarrow t \geq T\right)$.

The intuition behind these results is best conveyed graphically. Figure 2 plots the conditional variance of the future rule as predicted $s$ periods in advance. ${ }^{11}$

At any moment $t$, statute law gives perfect certainty of $x_{t}$ but not of $x_{t+s}$. Whenever the preferences of the legislature vary, the law is open to arbitrary change: its variance jumps discontinuously and tends toward its asymptotic value $\hat{\sigma}_{\mathrm{L}}^{2}$. On the contrary, case law never provides complete short-run certainty, but the conditional variance of future law increases smoothly and ever more slowly as the horizon lengthens and tends toward a lower asymptotic value if judges are sufficiently bound by stare decisis. This confirms Leoni's (1961) fundamental insight that the long-run certainty of judge-made law is higher than that of statute law.

11. The graph is drawn for $\hat{\sigma}_{\mathrm{J}}^{2}=4 \hat{\sigma}_{\mathrm{L}}^{2}=1, \psi=.85$, and $\Delta=0$. 


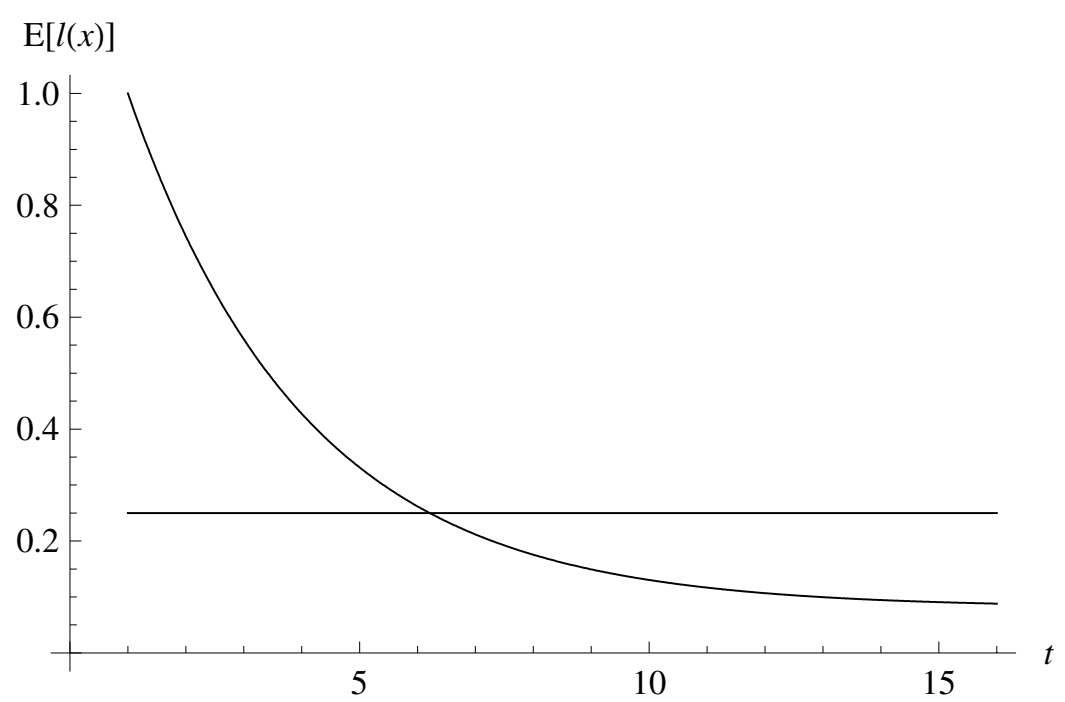

Figure 3. Ex ante expected loss from case law and statutes

Figure 3 plots the expected efficiency of the realized legal rule as a function of the length of the evolution of the system. ${ }^{12}$

The quality of statute law is entirely determined by the extent to which the legislature's preferences are aligned with social welfare. Instead, the quality of judge-made law does not derive primarily from the wisdom of individual judges but rather from the accumulated value of the tradition embodied in case law.

Proposition 1 showed that if precedents are entitled to substantial respect, case law tends asymptotically to ultimate efficiency. This also implies that case law is expected to achieve a better rule than statutes do, no matter how favorable to the former a static comparison between the legislature and the judiciary may appear (that is, no matter how small $\hat{\sigma}_{\mathrm{L}}^{2} / \hat{\sigma}_{\mathrm{J}}^{2}>0$ ).

As Figure 3 suggests, the convergence of case law makes it, on average, more efficient than statute law after a surprisingly brief evolution. Figure 4 shows the length of evolution $T$ required for case law to yield greater expected efficiency than statutes do, as a function of the relative representativeness of the judiciary compared to the legislature. ${ }^{13}$ Unless

12. The graph is drawn for $\hat{\sigma}_{\mathrm{J}}^{2}=4 \hat{\sigma}_{\mathrm{L}}^{2}=1$ and $\psi=.85$.

13. The graph plots the minimum $T$ as a function of $\psi$ taking $\hat{\sigma}_{\mathrm{L}}^{2} / \hat{\sigma}_{\mathrm{J}}^{2}$ as given. 


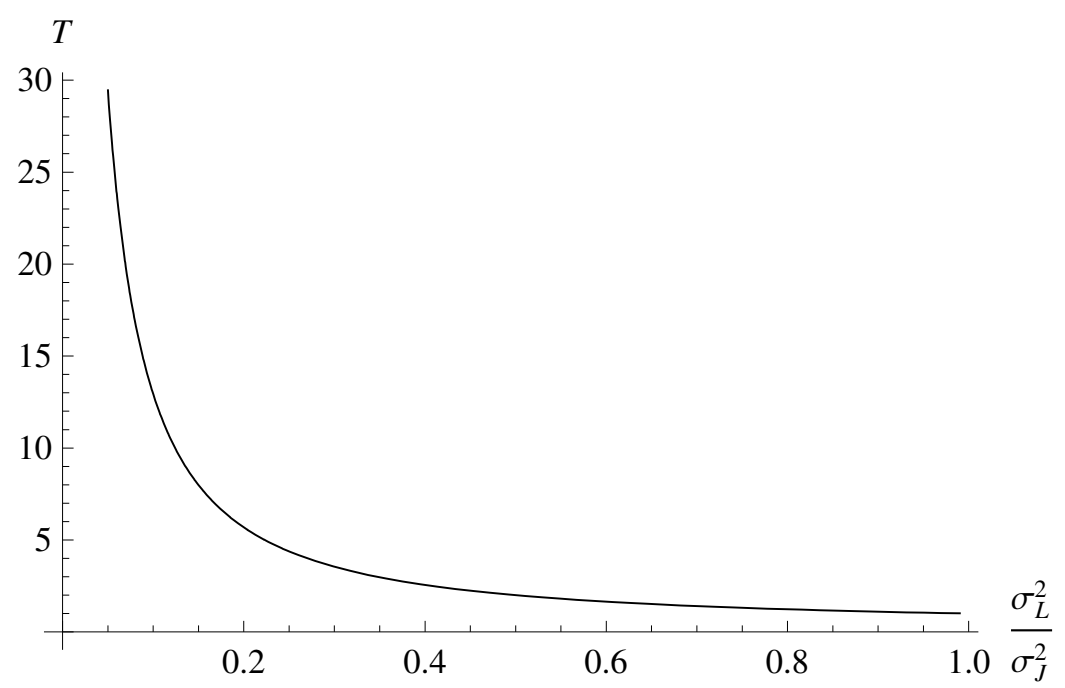

Figure 4. The horizon of expected superiority of case law

judges are tremendously prone to the influence of litigants (that is, unless $\hat{\sigma}_{\mathrm{L}}^{2} \hat{\sigma}_{\mathrm{J}}^{2}$ is very low), very few precedents suffice to reap the efficiency benefits of legal evolution.

Finally, the comparative appeal of judge-made law is further enhanced by the fact that a forward-looking society is not concerned with current efficiency alone but also is concerned with the future. This makes case law more attractive, because of the anticipated benefits of its future evolution. At any time, case law is expected to achieve greater social welfare than is statute law if, but not only if, it is expected to be currently more efficient. In fact, if society is sufficiently patient, the expected welfare will be greater under case law, for any horizon, including $t=1$, because social welfare is essentially determined by the long-run asymptotic behavior. ${ }^{14}$

The asymptotic superiority of case law is such that we can present stronger results that go beyond expected efficiency by taking a normal approximation of the underlying distributions $\hat{x}^{\mathrm{J}}$ and $\hat{x}^{\mathrm{L}}$. Figure 5 shows, as a function of the relative representativeness $\hat{\sigma}_{\mathrm{I}}^{2} \hat{\sigma}_{\mathrm{J}}^{2}$, the probability that asymptotic case law has achieved a more efficient rule than has statute

14. This result obtains if the social discount factor is $\beta \geq 1-\left(\hat{\sigma}_{\mathrm{L}}^{2} / \hat{\sigma}_{\mathrm{J}}^{2}\right)^{2}$, letting $\psi$ be determined as a function of $\beta$ to maximize the expected social welfare. 


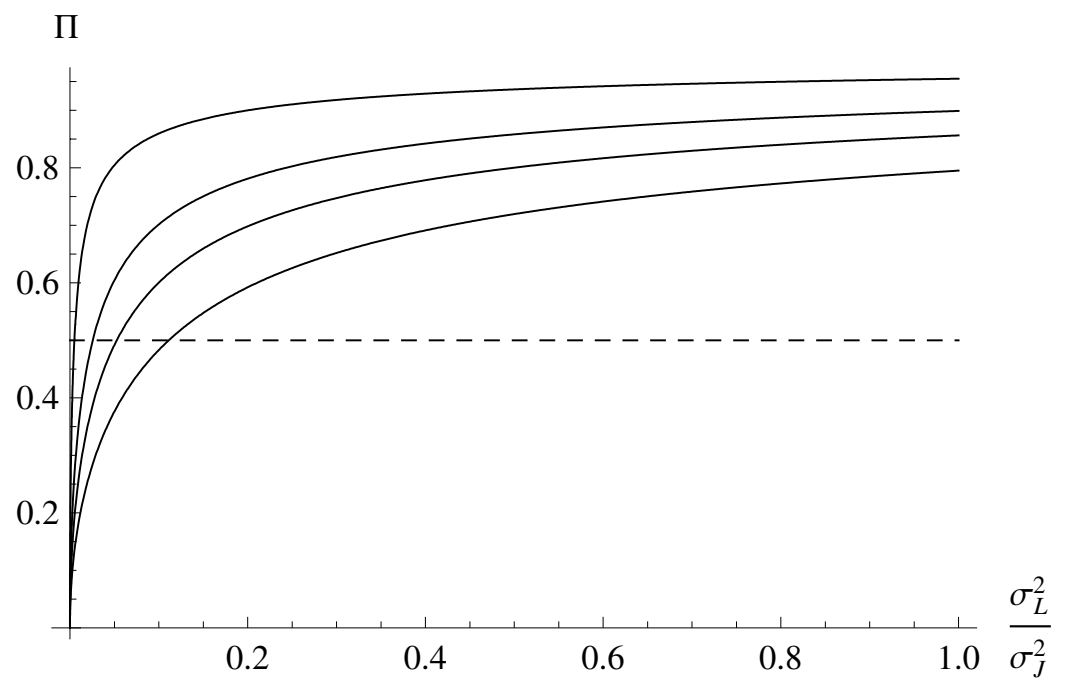

Figure 5. The probability that case law is more efficient than statutes

law, given different values of the institutional importance of precedent. ${ }^{15}$ The dashed line at .5 provides a reference point indicating when case law and statutes are statistically indistinguishable.

We conclude that in a stationary environment, the evolution of case law is not only expected but almost sure to lead to better results than does statute law in the long run.

\section{SOCIAL CHANGE AND COMMON LAW}

The results in the previous section on the long-run optimality of case law might appear puzzling in the light of the ever-increasing role of statutes in common law. Although England has known legislation since the Middle Ages, before the twentieth century it was used sparingly and reluctantly. This view has been progressively abandoned, and statutes and regulations now abound in Britain and the United States (Pound 1908; Scalia 1997), to the point that Calabresi (1982) speaks of the "statutorification" of American law.

This gradual modification of common-law institutions can be ex-

15. The values plotted are $\psi=.99, .95, .9$, and .8 from top to bottom. 
plained by a deficiency of stare decisis that could not be captured in a stationary model: reliance on precedent hinders the ability of case law to adapt to changing circumstances (Hayek 1973; Hathaway 2001). English statutes since their earliest use have been seen as a reaction to the unresponsiveness of the common law to the circumstances of society (Scheb and Scheb 2002). As a recent example, the Sarbanes-Oxley Act is widely regarded as a statutory response to the slowness and adherence to precedents of Delaware courts (Chandler and Strine 2003).

Moreover, this use of statutes should not be construed as a pure alternative to case law. In fact, contemporary common law is best understood as a mixed system in which both legislation and jurisprudence have complementary roles in the creation of the law. The legislature intervenes in the evolution of the law by introducing statutes, but according to the established canons of statutory interpretation these statutes are incorporated by the courts into the body of common law and are interpreted and developed according to the principle of stare decisis (Eskridge, Frickey, and Garrett 2000; Jellum and Hricik 2006).

The emergence of new circumstances that require legal adaptation is modeled by changes in the social optimum, $x_{t}^{*}$. We assume that technological innovation, social change, and current events shift the whole distribution of bliss points, which leaves the individuals' relative preferences unchanged. The social optimum, $x_{t}^{*}$, follows a jump process with a constant hazard rate $\lambda \in[0,1]$ and independent and identically distributed random increments $\xi$ with mean zero and variance $\sigma_{\xi}^{2}>0$.

Major shifts affecting all of society are followed in practice by legislative activity, either from parliament or even, in cases of real or pretended emergency, by the executive. Stark examples come from the nineteenth century: industrialization, the construction of railroads, and the emergence of big business led to increased legislative activity and the rise of the regulatory state (Glaeser and Shleifer 2003). To this day, much statute writing is event driven: we need only think of the legislative consequences of the 9/11 terrorist attacks or the Enron scandal (Chandler and Strine 2003; Butler and Ribstein 2006; Clark 2005).

In our model of the mixed system, every jump is followed by a legislative response: a statute is enacted, with expectation $x_{t}^{*}$ and variance $\hat{\sigma}_{\mathrm{L}}^{2}$. Just as in the stationary case, legislation is imperfect, and in fact it is not even guaranteed that the new rule is socially preferable to the one it replaces-although this is likely when the magnitude of social change 
is large and the quality of the political process is high, it is never certain. ${ }^{16}$

Furthermore, the legislature always desires an opportunity to exploit its lawmaking authority. We do not explicitly model the unwritten norms that determine the social acceptability of legislative intervention in the absence of social change but simply assume that such an opportunity arises with probability $1-\alpha$. Intuitively, in the absence of legislation, the courts gradually improve legal rules; therefore, it is socially desirable to prevent arbitrary intervention by rulers. Hence, we interpret the parameter $\alpha \in[0,1]$ as a measure of political accountability.

Focusing on the steady state, when the conditions of each system do not depend on the particular realization of the first legal rule, we prove the following:

Proposition 6. Pure statute law $(\psi=1)$ is optimal if, and only if, legislation is perfect $\left(\hat{\sigma}_{\mathrm{L}}^{2}=0\right)$; nonetheless, it is preferable to any system of pure case law if social change is sufficiently intense $\left(\lambda \sigma_{\xi}^{2}>\hat{\sigma}_{\mathrm{L}}^{4} /\left(\hat{\sigma}_{\mathrm{J}}^{2}-\hat{\sigma}_{\mathrm{L}}^{2}\right)\right)$.

The optimal system is pure case law when the social optimum is sufficiently stable and a mixed system when it is more volatile (that is, when $\sigma_{\xi}^{2}$ is greater than a threshold $\left.\Xi\left(\hat{\sigma}_{J}^{2}, \hat{\sigma}_{\mathrm{L}}^{2}, \alpha, \lambda\right)\right)$.

The mixed system is more likely to be optimal when the extent of judicial biases is greater $\left(\partial \Xi / \partial \hat{\sigma}_{J}^{2}<0\right)$, legislative preferences are more aligned with social welfare $\left(\partial \Xi / \partial \hat{\sigma}_{\mathrm{L}}^{2}>0\right)$, the legislature is more accountable $(\partial \Xi / \partial \alpha<0)$, and social change is more frequent $(\partial \Xi / \partial \lambda<0)$.

The first result simultaneously reinforces and qualifies our previous finding on the inefficiency of statutes in a stationary setting. Pure statute law is never desirable, but in the face of social change stare decisis can be an intolerable burden on case law. Although an answer to evolving social conditions could come from making judges less bound to precedent, this would defeat the very convergence property that makes case law desirable to begin with. Since $\hat{\sigma}_{J}^{2}>\hat{\sigma}_{\mathrm{L}}^{2}$, it is preferable that the authority to make laws without reference to precedent should be given to the legislature rather than the judiciary. Therefore, the better pure system to face intense social change is pure statute law.

The second part of the proposition makes it clear that the meaningful efficiency comparison is between a system of pure case law and a mixed system. Either can be optimal depending on the intensity of social

16. For example, it has been suggested that the Sarbanes-Oxley Act was a hasty and on many accounts inefficient legislative response to corporate scandals (Clark 2005; Butler and Ribstein 2006). 
change, but the mixed system is always better than pure statute law. The fundamental trade-off is between evolution toward efficiency when the social optimum does not change and rapid legal innovation when it does. The problem with the mixed system is that statutory intervention enables the legislature to adapt the law not only to the novel requirements of society but also to its own biases or the preferences of the special-interest groups that influence it. This price is worth paying only when social change is sufficiently intense.

The comparative statics are intuitive. Less intense social change is required for legislative intervention to be optimal when judges are worse and legislators are better: the disruption of the evolution of case law is then less costly because the evolution itself is less beneficial, and any statute being introduced is more likely to be an improvement. Statute writing is more likely to be detrimental when legislators are less accountable because they are more likely to introduce statutes unwarranted by changing circumstances. The more frequent is social change, the more likely that a mixed system will be preferred, since the problems deriving from the inertia of judge-made law will be more prominently displayed.

The predictions of proposition 6 receive support from the history of common law. In ancient times, English society may have been so static that pure case law was efficient, but in the modern era, common law has certainly become a mixed system in which the explicit role of legislation is supported by the increased democratic representativeness of parliamentary institutions. As the pace of technological, economic, and social change has accelerated over the last 2 centuries, so has legislative activity intensified.

In addition to the presence or absence of legislation as a source of law, a legal system is characterized by the institutional importance of precedent $\psi$. Specifically,

Corollary 3. The optimal importance of precedent for pure case law is decreasing in the intensity of social change $\left(\partial \psi_{J}^{*} / \partial\left(\lambda \sigma_{\xi}^{2}\right)<0\right)$ and increasing in the heterogeneity of judicial biases $\left(\partial \psi_{J}^{*} / \partial \hat{\sigma}_{J}^{2}>0\right)$.

The optimal importance of precedent for the mixed system is decreasing in the frequency of social change $\left(\partial \psi_{\mathrm{J}+\mathrm{L}}^{*} / \partial \lambda<0\right)$ and increasing in the heterogeneity of judicial biases $\left(\partial \psi_{J}^{*} / \partial \hat{\sigma}_{J}^{2}>0\right)$, in the accountability of the legislature $\left(\partial \psi_{\mathrm{J}+\mathrm{L}}^{*} / \partial \alpha>0\right)$, and in the alignment of its preferences with the social optimum $\left(\partial \psi_{\mathrm{J}+\mathrm{L}}^{*} / \partial \hat{\sigma}_{\mathrm{L}}^{2}<0\right)$.

For pure case law, the trade-off is between the speed of convergence and its eventual precision. The former becomes more important when 
social change is more intense, which leads to a lower optimal emphasis on stare decisis; the latter becomes more important when judges' preferences are more likely to deviate from the social optimum, and therefore a higher institutional respect for precedent is optimally required to constrain them.

For the mixed system, the comparative statics are equally intuitive. The magnitude of changes in the social optimum $\left(\sigma_{\xi}^{2}\right)$ is no longer directly relevant, since it will be dealt with by legislation. Instead, precedent should be more important when judicial preferences are worse and when statutes are better (namely, when $\hat{\sigma}_{\mathrm{J}}^{2}$ is higher and $\hat{\sigma}_{\mathrm{L}}^{2}$ is lower), because legislation provides the starting point for jurisprudential interpretation. ${ }^{17}$ More intense legislative change, resulting from either rapid social change (high $\lambda$ ) or limited accountability (low $\alpha$ ), pushes toward a less strict reliance on stare decisis, so courts have the ability to refine the enacted rule before it is superseded by a new statute.

These comparative statics are reflected in the historical evolution of common law. With the increasing variability of social conditions and the improvement of political institutions, not only has the use of statutes become more prevalent, but adherence to precedent has also become less strict in America and Britain (Glendon 1984; Zweigert and Kötz 1998).

\section{INTERNATIONAL EVIDENCE}

Our results on the inefficiency of pure statute law naturally underpin a critical assessment of the civil-law tradition of continental Europe, whose defining feature has been reliance on the "abstractly formulated authoritative text" (Glendon, Gordon, and Carozza 1999, p. 25). The mixed system can be seen not only as a portrayal of the introduction of legislation in a common-law system based on case law but also as the introduction of jurisprudence in a civil-law system based on statute law. In fact, the latter view yields a starker and more generic result than proposition 6 . For any specification of the process of social and political change, we can prove the following:

Proposition 7. The introduction of precedent-bound judicial inter-

17. In the limit case, perfect statutes $\left(\hat{\sigma}_{\mathrm{L}}^{2}=0\right)$ should not be subject to any judicial interpretation $\left(\psi^{*}=1\right)$. 
pretation in a statute law system increases social welfare. Social welfare is monotone increasing in political accountability.

The proposition highlights the unambiguous benefits of judicial interpretation of written statutes. This is perhaps unsurprising, since we have shown that case law introduces a desirable convergence of legal rules. The benefit arises over any length of time: the key is that every judge's bias is more likely to counteract than to exacerbate the legislature's bias. The advantage is naturally magnified by the accumulation of precedents by judges with different attitudes. This is both the rationale for institutionalizing precedent and the intuition behind the second part of the proposition. New legislation interrupts the evolutionary process of interpretation and is therefore unwelcome if it is not a reaction to changes in social preferences but merely a manifestation of the rulers' power.

Intuitive as the result may seem, it contradicts the most traditional view of civil law. Dawson (1968, p. 426) quotes Robespierre's statement that "the word jurisprudence . . . must be effaced from our language," and Damaska (1986, p. 37) reports that in postrevolutionary France, "the judge was to be only la bouche (the mouthpiece), not le cerveau (the brains), of the law."

Our theoretical analysis, which has emphasized the efficiency advantage of judge-made law, thus provides an explanation for the robust statistical significance of legal origins in cross-country regressions explaining financial, economic, and political efficiency (La Porta et al. 1997, 1998, 1999, 2004; La Porta, Lopez-de-Silanes, and Shleifer 2002; Mahoney 2001; Beck, Demirgüç-Kunt, and Levine 2003b; Mulligan and Shleifer 2005; Djankov, McLiesh, and Shleifer 2007; Djankov et al. 2008). In spite of overwhelming evidence that common-law countries achieve better average outcomes than do French civil-law countries, the reasons for these systematic differences have not been made entirely clear yet. The appeal of our explanation based on the importance of judgemade law goes beyond the generic association of the common-law and civil-law traditions, respectively, with case law and statutes but is supported by a more detailed analysis of the empirical evidence.

The weight accorded to precedent is higher in Germany than in France, which reflects the two countries' different intellectual traditions (Zweigert and Kötz 1998; Glendon, Gordon, and Carozza 1999). Scandinavian systems, which never adopted full codification, have been characterized as hybrids (Bankowski et al. 1997). Empirically, the evidence 
on the effect of legal origins on financial and economic outcomes shows that stark differences are always to be found between common-law countries and French civil-law countries (the former outperforming the latter), while German and Scandinavian civil-law countries occupy an intermediate position and sometimes do not significantly differ from common-law countries (La Porta et al. 1997, 1998, 1999).

Moreover, Beck, Demirgüç-Kunt, and Levine (2003a, 2005) explore in greater detail two different channels whereby legal origins may affect the quality of legal institutions and, ultimately, financial development: the first is judicial independence from other branches of government; the second is the importance of judicial precedent as a source of law. Both cross-country regressions and firm-level panel data analysis reject the judicial independence channel, finding instead support for the case law channel alone in explaining the ranked differences between common law, German civil law, and French civil law.

Furthermore, a case could be made that this evidence understates the importance of judge-made law. The data on the role of case law in different jurisdictions are collected by La Porta et al. (2004) from David (1973), which reports each country's formal statements on the operation of its legal system. In other words, they reflect "law in books" and not "law in action" (Pound 1910). Legal scholarship has suggested the presence of a systematic deviation between the two. French courts pay lip service to the rhetoric of statutory justification of all their decisions while in practice increasingly behave like their common-law counterparts (Lasser 1995; Zweigert and Kötz 1998). This trend is present in most European countries but less prevalent in their former colonies and other countries into which the Napoleonic legal system was transplanted (Merryman 1996). For example, recent analyses of the Latin American experience bear out the persistence of the most traditional view of the separation of powers, as well as the increasing awareness of a need for judicial reform (MacLean 1982; Linarelli 1996; Sáez 1998; Landau 2005; Sieder, Schjolden, and Angell 2005).

These considerations shed new light on Berkowitz, Pistor, and Richard's (2003) findings on the "transplant effect." Their empirical analysis shows that the process by which a legal system was transplanted into countries beyond the one where it originated is at least as important as the legal origin per se in explaining economic outcomes. In particular, transplants are classified as "unreceptive" when the transplanted legal rules are not clearly understood in the receiving country. The conclusion is that the significant explanatory variables are unreceptive transplant, 
410 / THE JOURNAL OF LEGAL STUdies / VOLUME 37 (2) / JUNE 2008

French legal origin, and Organisation for Economic Co-operation and Development (OECD) membership and specifically that "the worst possible outcome is to be an unreceptive transplant that has received the French code and is not a member of the OECD" (p. 185).

This result is consistent with our view that a fundamental determinant of efficiency is case law, which exists not only in common-law countries but also (if to a lesser extent) in the German and Scandinavian traditions and in those legal systems that either at the time of the transplant or through subsequent intra-European discourse were able to understand and adopt the actual substance, rather than merely the superficial formalism, of French civil law.

In fact, proposition 7 suggests that powerful efficiency pressures to recognize the lawmaking role of judges must exist in civil law. This prediction finds confirmation in the contemporary evolution of continental European legal systems, in which the decisive and increasing role of civil-law judges in the interpretation of statutes and the development of legal rules is widely acknowledged (David and de Vries 1958; Dale 1977; Glendon 1984; David and Brierley 1985; Merryman 1985; Bankowski et al. 1997; Germain 2003). Merryman (1996, p. 113) concludes that continental "courts, like courts everywhere, find it convenient, economical and fair to decide new cases consistently with their decisions in prior cases." The model of judicial activity presented in proposition 6 is increasingly applicable not only to common-law courts but also to their civil-law counterparts.

All in all, a considerable legal literature documents the gradual emergence of a hybrid of the jurisprudential and legislative lawmaking technologies and the resulting convergence of common-law and civil-law systems in terms of substantive outcomes (Coudert 1913; Troper and Grzegorczyk 1997; Zweigert and Kötz 1998; Glendon, Gordon, and Carozza 1999; Coffee 2002; Hertig 2004).

Our model explains this development as a response to social pressures to adopt more efficient institutions. Propositions 6 and 7 have shown that intense social change creates incentives to add legislation to the body of case law, which increases the use of statutes in common law. Civil-law countries, too, have witnessed "legislative inflation" (Debbasch 1986; Döring 1995; Eng 2002), but, according to proposition 7, no amount of statute writing is optimal without judicial interpretation. Hence, the main efficiency pressure in civil law is to increase the scope of case law. 


\section{CONCLUSION}

Posner's claim that common law tends toward efficiency has been one of the most influential ideas in law and economics. In this paper, we have provided a formal model that confirms this convergence hypothesis. The evolution of case law is beneficial because it generates a sequential interaction between a series of judges with different preferences, whose idiosyncrasies then balance one another. Stare decisis implies that rulings that deviate from precedent are personally costly to the judge. Through the decisions of judges with heterogeneous biases, case law develops as a never-ending process that evolves toward greater predictability and efficiency.

Legislatures are expected to be more democratically representative than are individual judges, whose decisions may reflect the pressures of powerful litigants. Moreover, statutes provide the short-run certainty of written law. But the evolution of case law provides better outcomes in the long run, unless the efficient rule is changing over time. When the optimum is highly mutable, common law should include a role for statutes to correct the rigidity of binding precedent. Yet statutes should be integrated in the body of case law and interpreted by precedent-bound courts.

Our theoretical analysis thus accounts for the modern history of common law, in which statutes have increasingly come to complement, but not substitute for, judge-made law. Moreover, the finding that pure statute law is never optimal explains the cross-country evidence showing that common-law countries tend to have more efficient institutions and superior financial and economic development than those belonging to the civil-law tradition.

To the extent that societies naturally tend to develop more efficient institutions, our model predicts the gradual convergence of traditionally disparate legal families toward an optimal system recognizing the complementary roles of legislation and judicial precedents as sources of law. There are signs of the emergence of such a mixed system in most developed countries. More broadly, establishing and securing the lawmaking role of judges and the ongoing judicial interpretation of statutes should be a priority of legal reform. 
412 / THE JOURNAL OF LEGAL STUdiES / VOLUME 37 (2) / JUNE 2008

\section{APPENDIX A: DERIVATION OF FORMAL RESULTS}

It will be useful to recall a few properties of the generic first-order linear autoregressive $(\mathrm{AR})$ model.

The difference equation of an $\mathrm{AR}(1)$ process

$$
x_{t+1}=a x_{t}+\varepsilon_{t+1}
$$

with autoregressive coefficient $a \in(0,1)$ implies the conditional distribution

$$
x_{t+s} \mid x_{t}=a^{s} x_{t}+\sum_{\tau=1}^{s} a^{s-\tau} \varepsilon_{t+\tau}
$$

and the unconditional distribution

$$
x_{t}=a^{t-1} x_{1}+\sum_{s=2}^{t} a^{t-s} \varepsilon_{s}
$$

where the starting point $x_{1}$ is itself a random variable.

Assume that the innovations $\varepsilon_{t}$ are independently and identically distributed with finite mean $E(\varepsilon)$ and finite variance $\operatorname{Var}(\varepsilon)$. Then the conditional moments are

$$
\begin{aligned}
E\left(x_{t+s} \mid x_{t}\right) & =\frac{E(\varepsilon)}{1-a}+a^{s}\left[x_{t}-\frac{E(\varepsilon)}{1-a}\right], \\
\operatorname{Var}\left(x_{t+s} \mid x_{t}\right) & =\frac{\operatorname{Var}(\varepsilon)}{1-a^{2}}-a^{2 s} \frac{\operatorname{Var}(\varepsilon)}{1-a^{2}}
\end{aligned}
$$

and the unconditional moments are

$$
\begin{aligned}
E\left(x_{t}\right) & =\frac{E(\varepsilon)}{1-a}+a^{t-1}\left[E\left(x_{1}\right)-\frac{E(\varepsilon)}{1-a}\right], \\
\operatorname{Var}\left(x_{t}\right) & =\frac{\operatorname{Var}(\varepsilon)}{1-a^{2}}+a^{2(t-1)}\left[\operatorname{Var}\left(x_{1}\right)-\frac{\operatorname{Var}(\varepsilon)}{1-a^{2}}\right] .
\end{aligned}
$$

The $\mathrm{AR}(1)$ process is stationary given $a \in(0,1)$ and converges to an ergodic distribution. Its moments converge geometrically, with respective factors of convergence $a$ and $a^{2}$, to the asymptotic moments

$$
\begin{aligned}
E(x) & =\frac{E(\varepsilon)}{1-a}, \\
\operatorname{Var}(x) & =\frac{\operatorname{Var}(\varepsilon)}{1-a^{2}} .
\end{aligned}
$$


By the central limit theorem, the asymptotic distribution is normal:

$$
x \sim N\left(\frac{E(\varepsilon)}{1-a}, \frac{\operatorname{Var}(\varepsilon)}{1-a^{2}}\right) .
$$

\section{Proof of Proposition 1}

The judge's optimization problem is globally convex, and its first-order condition is

$$
x_{t+1}^{\mathrm{J}}=\psi x_{t}^{\mathrm{J}}+(1-\psi) \hat{x}_{t+1}^{\mathrm{J}},
$$

which is the difference equation (equation [A1]) of an $\mathrm{AR}(1)$ process with autoregression coefficient $a=\psi$ and innovation $\varepsilon_{t}=(1-\psi) \hat{x}_{t}^{\mathrm{J}}$.

Thus, equations (A2) and (A4) imply that given any current rule $x_{t}^{\mathrm{J}}$, the future rule $x_{t+s}^{\mathrm{J}}$ can be expressed as

$$
x_{t+s}^{\mathrm{J}} \mid x_{t}^{\mathrm{J}}=\psi^{s} x_{t}^{\mathrm{J}}+(1-\psi) \sum_{\tau=1}^{s} \psi^{s-\tau} \hat{x}_{t+\tau}^{\mathrm{J}}
$$

with moments

$$
\begin{aligned}
E\left(x_{t+s}^{\mathrm{J}} \mid x_{t}^{\mathrm{J}}\right) & =x^{*}+\psi^{s}\left(x_{t}^{\mathrm{J}}-x^{*}\right), \\
\operatorname{Var}\left(x_{t+s}^{\mathrm{J}} \mid x_{t}^{\mathrm{J}}\right) & =\left(1-\psi^{2 s}\right) \frac{1-\psi}{1+\psi}
\end{aligned}
$$

such that the conditional expectation $E\left(x_{t+s}^{\mathrm{J}} \mid x_{t}^{\mathrm{J}}\right)$ converges to $x^{*}$ with a factor of convergence $\psi$.

Moreover, equations (A3) and (A5) imply that, after $t$ periods of evolution, case law $x_{t}^{\mathrm{J}}$ can be expressed as

$$
x_{t}^{\mathrm{J}}=\psi^{t-1} \hat{x}_{1}^{\mathrm{J}}+(1-\psi) \sum_{s=2}^{t} \psi^{t-s} \hat{x}_{s}^{\mathrm{J}}
$$

with moments

$$
\begin{aligned}
E\left(x_{t}^{\mathrm{J}}\right) & =x^{*} \\
\operatorname{Var}\left(x_{t}^{\mathrm{J}}\right) & =\frac{1-\psi}{1+\psi} \hat{\sigma}_{\mathrm{J}}^{2}+2 \frac{\psi^{2 t-1}}{1+\psi} \hat{\sigma}_{\mathrm{J}}^{2} .
\end{aligned}
$$

The asymptotic distribution (equation [A7]) of case law is

$$
x^{\mathrm{J}} \sim N\left(x^{*}, \frac{1-\psi}{1+\psi} \hat{\sigma}_{\mathrm{J}}^{2}\right) .
$$


Proof of Corollary 1

Over $s$ periods, the law undergoes a random number of changes that is independent of judges' preferences and obeys a binomial distribution with probability mass function

$$
P(c)=\frac{s !}{c !(s-c) !} p^{c}(1-p)^{s-c}
$$

Given any current rule $x_{t}^{\mathrm{J}}$, the moments of the future rule $x_{t+s}^{\mathrm{J}}$ can be expressed as a function of the probability that $c$ changes will occur and the moments conditional on exactly $c$ changes occurring:

$$
\begin{aligned}
E\left(x_{t+s}^{\mathrm{J}} \mid x_{t}^{\mathrm{J}}\right) & =\sum_{c=0}^{s} P(c) E\left(x_{t+s}^{\mathrm{J}} \mid x_{t}^{\mathrm{J}}, c\right), \\
\operatorname{Var}\left(x_{t+s}^{\mathrm{J}} \mid x_{t}^{\mathrm{J}}\right) & =\sum_{c=0}^{s} P(c)\left\{\operatorname{Var}\left(x_{t+s}^{\mathrm{J}} \mid x_{t}^{\mathrm{J}}, c\right)+\left[E\left(x_{t+s}^{\mathrm{J}} \mid x_{t}^{\mathrm{J}}, c\right)\right]^{2}\right\}-\left[E\left(x_{t+s}^{\mathrm{J}} \mid x_{t}^{\mathrm{J}}\right)\right]^{2} .
\end{aligned}
$$

The moments conditional on exactly $c$ changes occurring are directly obtained from equation (A10):

$$
\begin{aligned}
E\left(x_{t+s}^{\mathrm{J}} \mid x_{t}^{\mathrm{J}}, c\right) & =x^{*}+\psi^{c}\left(x_{t}^{\mathrm{J}}-x^{*}\right), \\
\operatorname{Var}\left(x_{t+s}^{\mathrm{J}} \mid x_{t}^{\mathrm{J}}, c\right) & =\left(1-\psi^{2 c}\right) \frac{1-\psi}{1+\psi} \hat{\sigma}_{\mathrm{J}}^{2},
\end{aligned}
$$

so, if we use Newton's binomial formula, equation (A15) can be solved to yield

$$
\begin{aligned}
E\left(x_{t+s}^{\mathrm{J}} \mid x_{t}^{\mathrm{J}}\right)= & x^{*}+(1-p+p \psi)^{s}\left(x_{t}^{\mathrm{J}}-x^{*}\right), \\
\operatorname{Var}\left(x_{t+s}^{\mathrm{J}} \mid x_{t}^{\mathrm{J}}\right)= & \frac{1-\psi}{1+\psi} \hat{\sigma}_{\mathrm{J}}^{2}-\left(1-p+p \psi^{2}\right)^{s} \frac{1-\psi}{1+\psi} \hat{\sigma}_{\mathrm{J}}^{2} \\
& +\left[\left(1-p+p \psi^{2}\right)^{s}-(1-p+p \psi)^{2 s}\right]\left(x_{t}^{\mathrm{J}}-x^{*}\right)^{2},
\end{aligned}
$$

which shows that the conditional expectation $E\left(x_{t+s}^{J} \mid x_{t}^{J}\right)$ converges to $x^{*}$ with a factor of convergence $1-p+p \psi$.

\section{Proof of Proposition 2}

Under this generalization, the evolution of case law is defined by the Markov chain

$$
x_{t+1}^{\mathrm{J}}= \begin{cases}x_{t}^{\mathrm{J}} & \text { with } \operatorname{Pr} 1-p\left(\left|x_{t}^{\mathrm{J}}-x^{*}\right|\right) \\ \psi x_{t}^{\mathrm{J}}+(1-\psi) \hat{x}_{t+1}^{\mathrm{J}} & \text { with } \operatorname{Pr} p\left(\left|x_{t}^{\mathrm{J}}-x^{*}\right|\right),\end{cases}
$$


whose transition probability function has point mass $1-p\left(\left|x_{t}-x^{*}\right|\right)$ at $x_{t}$ and density on $\mathbb{R}$ of

$$
\pi\left(x_{t+1}^{\mathrm{J}} \mid x_{t}^{\mathrm{J}}\right)=p\left(\left|x_{t}^{\mathrm{J}}-x^{*}\right|\right) \hat{f}_{\mathrm{J}}\left(\frac{x_{t+1}^{\mathrm{J}}-\psi x_{t}^{\mathrm{J}}}{1-\psi}\right)
$$

where $\hat{f}_{\mathrm{J}}\left(\hat{x}^{\mathrm{J}}\right)$ denotes the density of the distribution of judges' preferences.

This Markov chain is irreducible, aperiodic, and positive recurrent. As a consequence, it has a unique stationary distribution that coincides with its asymptotic distribution. This is a continuous distribution whose density $\mu\left(x^{\mathrm{J}}\right)$ is implicitly defined by the steady-state equation

$$
\mu\left(x^{\mathrm{J}}\right)=\left[1-p\left(\left|x^{\mathrm{J}}-x^{*}\right|\right)\right] \mu\left(x^{\mathrm{J}}\right)+\int_{-\infty}^{\infty} p\left(\left|y-x^{*}\right|\right) \hat{f}_{\mathrm{J}}\left(\frac{x^{\mathrm{J}}-\psi y}{1-\psi}\right) \mu(y) d y .
$$

Since $\hat{x}^{\mathrm{J}} \sim N\left(x^{*}, \hat{\sigma}_{\mathrm{J}}^{2}\right)$, the solution can be exactly computed as

$$
\mu\left(x^{\mathrm{J}}\right)=\kappa \frac{\varphi\left(x^{\mathrm{J}}\right)}{p\left(\left|x^{\mathrm{J}}-x^{*}\right|\right)},
$$

where $\varphi\left(x^{J}\right)$ is the density of a normal distribution with mean $x^{*}$ and variance $\hat{\sigma}_{J}^{2}(1-\psi) /(1+\psi)$, and the scale constant $\kappa=1 /\left[\int_{-\infty}^{\infty}(\varphi(y) / p(y)) d y\right]$ ensures that $\mu($.$) is properly normalized as a probability density.$

The expectation of the asymptotic distribution is

$$
E\left(x^{\mathrm{J}}\right)=\int_{-\infty}^{\infty} \kappa \frac{\varphi\left(x^{\mathrm{J}}\right)}{p\left(\left|x^{\mathrm{J}}-x^{*}\right|\right)} d x^{\mathrm{J}}=x^{*}
$$

since both $p\left(\left|x^{\mathrm{J}}-x^{*}\right|\right)$ and $\varphi\left(x^{\mathrm{J}}\right)$ are symmetric around $x^{*}$, and the variance is

$$
\operatorname{Var}\left(x^{\mathrm{J}}\right)=\frac{\int_{-\infty}^{\infty}\left(x^{\mathrm{J}}-x^{*}\right)^{2}\left[\varphi\left(x^{\mathrm{J}}\right) / p\left(\left|x^{\mathrm{J}}-x^{*}\right|\right)\right] d x^{\mathrm{J}}}{\int_{-\infty}^{\infty}\left[\varphi(y) / p\left(\left|y-x^{*}\right|\right)\right] d y}<\frac{1-\psi}{1+\psi} \hat{\sigma}_{\mathrm{J}}^{2} .
$$

The last inequality can be established by observing that $\phi(z)$ is the density of

$$
z \sim N\left(x^{*}, \frac{1-\psi}{1+\psi} \hat{\sigma}_{J}^{2}\right)
$$

so

$$
\operatorname{Var}\left(x^{\mathrm{J}}\right)=\frac{1-\psi}{1+\psi} \hat{\sigma}_{\mathrm{J}}^{2}+\frac{\operatorname{Cov}\left[\left(p\left(\left|z-x^{*}\right|\right)\right)^{-1},\left(z-x^{*}\right)^{2}\right]}{E\left[\left(p\left(\left|z-x^{*}\right|\right)\right)^{-1}\right]},
$$

whose second term is negative because both $\left(p\left(\left|z-x^{*}\right|\right)\right)^{-1}$ and $\left(z-x^{*}\right)^{2}$ are everywhere nonnegative and because their derivatives have opposite signs on $\mathbb{R}$. 
416 / THE JOURNAL OF LEGAL STUdiES / VOLUME 37 (2) / JUNE 2008

Proof of Proposition 3

The loss to the judge as a function of his or her ruling is

$$
L_{\mathrm{J}}\left(x_{t}^{\mathrm{J}}\right)=(1-\psi) \sum_{s=0}^{\infty} \beta_{\mathrm{J}}^{s}\left[\left(E\left(x_{t+s}^{\mathrm{J}} \mid x_{t}^{\mathrm{J}}\right)-\hat{x}_{t}^{\mathrm{J}}\right)^{2}+\operatorname{Var}\left(x_{t+s}^{\mathrm{J}} \mid x_{t}^{\mathrm{J}}\right)\right]+\psi\left(x_{t}^{\mathrm{J}}-x_{t-1}^{\mathrm{J}}\right)^{2},
$$

which encompasses the case analyzed in proposition 1 for $\beta_{\mathrm{J}}=0$.

We are interested in an equilibrium analogous to the nonstrategic behavior depicted in proposition 1 , such that all judges follow a linear rule

$$
x_{t+1}^{\mathrm{J}}=a x_{t}^{\mathrm{J}}+(1-a) \hat{x}_{t+1}^{\mathrm{J}}+b\left(\hat{x}_{t+1}^{\mathrm{J}}-x^{*}\right)
$$

for some parameters $a \in(0,1)$ and $b>0$ determined below.

Equation (A25) is the difference equation (A1) of an $\mathrm{AR}(1)$ process with autoregression coefficient $a$ and innovation $\varepsilon_{t}=(1-a+b) \hat{x}_{t}^{\mathrm{J}}-b x^{*}$. Thus, when all future judges follow the strategy expressed in equation (A25), equations (A2) and (A4) imply that given any current rule $x_{t}^{J}$, the future rule $x_{t+s}^{J}$ can be expressed as

$$
x_{t+s}^{\mathrm{J}} \mid x_{t}^{\mathrm{J}}=a^{s} x_{t}^{\mathrm{J}}+(1-a+b) \sum_{\tau=1}^{s} a^{s-\tau} \hat{x}_{t+\tau}^{\mathrm{J}}-\frac{1-a^{s}}{1-a} b x^{*}
$$

with moments

$$
\begin{aligned}
E\left(x_{t+s}^{\mathrm{J}} \mid x_{t}^{\mathrm{J}}\right) & =x^{*}+a^{s}\left(x_{t}^{\mathrm{J}}-x^{*}\right), \\
\operatorname{Var}\left(x_{t+s}^{\mathrm{J}} \mid x_{t}^{\mathrm{J}}\right) & =\left(1-a^{2 s}\right) \frac{(1-a+b)^{2}}{1-a^{2}} \hat{\sigma}_{\mathrm{J}}^{2} .
\end{aligned}
$$

As a consequence, when all future judges follow the strategy expressed in equation (A25), each judge's best response is to set

$x_{t}^{\mathrm{J}}=\frac{\psi\left(1-\beta_{\mathrm{J}} a^{2}\right)}{1-\beta_{\mathrm{J}} \psi a^{2}} x_{t-1}^{\mathrm{J}}+\frac{(1-\psi)\left(1-\beta_{\mathrm{J}} a^{2}\right)}{\left(1-\beta_{\mathrm{J}} a\right)\left(1-\beta_{\mathrm{J}} \psi a^{2}\right)} \hat{x}_{t}^{\mathrm{J}}-\frac{(1-\psi) \beta_{\mathrm{J}} a(1-a)}{\left(1-\beta_{\mathrm{J}} a\right)\left(1-\beta_{\mathrm{J}} \psi a^{2}\right)} x^{*}$,

which is itself a linear rule.

For any $\psi \in(0,1)$, the best response-expressed in equation (A28)—coincides with the equilibrium strategy expressed in equation (A25) for a unique pair of parameters that can be obtained by the method of undetermined coefficients:

$$
\begin{aligned}
& a \in(0, \psi) \quad \text { such that } \beta_{\mathrm{J}} \psi a^{3}-\beta_{\mathrm{J}} \psi a^{2}-a+\psi=0, \\
& b=\frac{\beta_{\mathrm{J}} a(1-a)^{2}}{1-\beta_{\mathrm{J}} a} \geq 0 .
\end{aligned}
$$


The equilibrium value of $a$ is well defined as the root of

$$
\Theta(a) \equiv \beta_{\mathrm{J}} \psi a^{3}-\beta_{\mathrm{J}} \psi a^{2}-a+\psi
$$

because the auxiliary function $\theta$ is continuous, monotone decreasing on $(0,1)$, positive at 0 , and negative at $\psi$, which implies a unique root $a \in(0, \psi)$ such that $\Theta(a)=0$.

The implicit-function theorem yields the unambiguous comparative statics:

$$
\begin{aligned}
& \frac{\partial a}{\partial \beta_{\mathrm{J}}}=\frac{(1-a) \psi a^{2}}{\Theta^{\prime}(a)}<0, \\
& \frac{\partial a}{\partial \psi}=-\frac{1-\beta_{\mathrm{J}} a^{2}(1-a)}{\Theta^{\prime}(a)}>0 .
\end{aligned}
$$

Given the equilibrium value of $b$, and keeping in mind the implicit definition of $a$, we see that the asymptotic distribution (equation [A7]) of case law is

$$
x^{\mathrm{J}} \sim N\left(x^{*}, \frac{1-a}{1+a}\left(\frac{1-\beta_{\mathrm{J}} a^{2}}{1-\beta_{\mathrm{J}} a}\right)^{2} \hat{\sigma}_{\mathrm{J}}^{2}\right),
$$

and the conditional moments (equation [A27]) reduce to

$$
\begin{aligned}
E\left(x_{t+s}^{\mathrm{J}} \mid x_{t}^{\mathrm{J}}\right) & =x^{*}+a^{s}\left(x_{t}^{\mathrm{J}}-x^{*}\right), \\
\operatorname{Var}\left(x_{t+s}^{\mathrm{J}} \mid x_{t}^{\mathrm{J}}\right) & =\left(1-a^{2 s}\right) \frac{1-a}{1+a}\left(\frac{1-\beta_{\mathrm{J}} a^{2}}{1-\beta_{\mathrm{J}} a}\right)^{2} \hat{\sigma}_{\mathrm{J}}^{2} .
\end{aligned}
$$

Thus, the conditional expectation $E\left(x_{t+s}^{\mathrm{J}} \mid x_{t}^{\mathrm{J}}\right)$ converges to $x^{*}$ with a factor of convergence $a$, and since $\partial a / \partial \beta_{\mathrm{J}}<0$, for all $s \geq 1$

$$
\begin{aligned}
\frac{\partial \operatorname{Var}\left(x_{t+s}^{\mathrm{J}} \mid x_{t}^{\mathrm{J}}\right)}{\partial \beta_{\mathrm{J}}}=2 \hat{\sigma}_{\mathrm{J}}^{2}\{( & \left(-a^{2 s}\right) \frac{a(1-a)^{2}\left(1-\beta_{\mathrm{J}} a^{2}\right)}{(1+a)\left(1-\beta_{\mathrm{J}} a\right)^{3}} \\
& -\frac{\partial a}{\partial \beta_{\mathrm{J}}}\left(1-a^{2 s}\right) \frac{\left(1-\beta_{\mathrm{J}} a^{2}\right)}{(1+a)^{2}\left(1-\beta_{\mathrm{J}} a\right)^{3}} \\
& \times\left[\left(1-\beta_{\mathrm{J}}\right)(1-a)+a(1-a)\left(1-\beta_{\mathrm{J}}^{2} a\right)+a^{2}\left(1-\beta_{\mathrm{J}} a\right)^{2}\right] \\
& \left.-\frac{\partial a}{\partial \beta_{\mathrm{J}}} s a^{2 s-1} \frac{1-a}{1+a}\left(\frac{1-\beta_{\mathrm{J}} a^{2}}{1-\beta_{\mathrm{J}} a}\right)^{2}\right\}>0 .
\end{aligned}
$$

Finally, to complete the characterization of the equilibrium, we may note that the strategy of the first judge, who faces no inherited rule, is $x_{1}^{\mathrm{J}}=\hat{x}_{1}^{\mathrm{J}}+$ $\left(\hat{x}_{1}^{\mathrm{J}}-x^{*}\right) \beta_{\mathrm{J}} a(1-a) /\left(1-\beta_{\mathrm{J}} a\right)$. 
418 / THE JOURNAL OF LEGAL STUdiES / VOLUME 37 (2) / JUNE 2008

Proof of Proposition 4

The legislature's optimal choice of $x_{t}^{\mathrm{L}}$ is described by

$$
x_{t}^{\mathrm{L}}= \begin{cases}x_{t-1}^{\mathrm{L}} & \text { if } \hat{x}_{t}^{\mathrm{L}} \in\left[x_{t-1}^{\mathrm{L}}-\sqrt{\Delta}, x_{t-1}^{\mathrm{L}}+\sqrt{\Delta}\right] \\ \hat{x}_{t}^{\mathrm{L}} & \text { if } \hat{x}_{t}^{\mathrm{J}} \notin\left[x_{t-1}^{\mathrm{L}}-\sqrt{\Delta}, x_{t-1}^{\mathrm{L}}+\sqrt{\Delta}\right],\end{cases}
$$

which directly yields a Markov transition probability with point mass

$$
P\left(x_{t}^{\mathrm{L}}\right)=\hat{F}_{\mathrm{L}}\left(x_{t}^{\mathrm{L}}+\sqrt{\Delta}\right)-\hat{F}_{\mathrm{L}}\left(x_{t}^{\mathrm{L}}-\sqrt{\Delta}\right)
$$

at $x_{t}^{\mathrm{L}}$ and density

$$
\pi\left(x_{t+1}^{\mathrm{L}} \mid x_{t}^{\mathrm{L}}\right)=\hat{f}_{\mathrm{L}}\left(x_{t+1}^{\mathrm{L}}\right)
$$

for every $x_{t+1}^{\mathrm{L}} \in \mathbb{R} \backslash\left[x_{t}^{\mathrm{L}}-\sqrt{\Delta}, x_{t}^{\mathrm{L}}+\sqrt{\Delta}\right]$.

A stationary distribution $G(x)$ for this Markov process has continuous density $g(x)$ satisfying

$$
\begin{aligned}
g\left(x^{\mathrm{L}}\right)= & {\left[\hat{F}_{\mathrm{L}}\left(x^{\mathrm{L}}+\sqrt{\Delta}\right)-\hat{F}_{\mathrm{L}}\left(x^{\mathrm{L}}-\sqrt{\Delta}\right)\right] g\left(x^{\mathrm{L}}\right) } \\
& +\hat{f}_{\mathrm{L}}\left(x^{\mathrm{L}}\right)\left[1-G\left(x^{\mathrm{L}}+\sqrt{\Delta}\right)+G\left(x^{\mathrm{L}}-\sqrt{\Delta}\right)\right],
\end{aligned}
$$

which is uniquely satisfied by $G\left(x^{\mathrm{L}}\right) \equiv \hat{F}_{\mathrm{L}}\left(x^{\mathrm{L}}\right)$; hence, the Markov chain is strictly stationary, and its unique steady-state distribution is also the asymptotic conditional distribution and the unconditional distribution for any period.

\section{Proof of Proposition 5}

The variance of $\hat{x}^{\mathrm{L}}$ is

$$
\begin{aligned}
\hat{\sigma}_{\mathrm{L}}^{2} & =\iota^{2} \frac{\sigma^{2}}{S} \in\left(0, \sigma^{2}\right) \\
& \Rightarrow \frac{\partial \hat{\sigma}_{\mathrm{L}}^{2}}{\partial \iota}=2 \iota \frac{\sigma^{2}}{S}>0,
\end{aligned}
$$

and the variance of $\hat{x}^{\mathrm{J}}$ is

$$
\begin{aligned}
\hat{\sigma}_{\mathrm{J}}^{2} & =\left\{[\iota+(1-\imath) b]^{2}+b^{2}(S-1)\right\} \frac{\sigma^{2}}{S} \in\left(\hat{\sigma}_{\mathrm{L}}^{2}, \sigma^{2}\right) \\
& \Rightarrow \frac{\partial \hat{\sigma}_{\mathrm{J}}^{2}}{\partial \iota}=2(1-b)[\iota+(1-\imath) b] \frac{\sigma^{2}}{S}>0 \\
& \Rightarrow \frac{\partial \hat{\sigma}_{\mathrm{J}}^{2}}{\partial b}=2\{(1-\iota)[\iota+(1-\iota) b]+b(S-1)\} \frac{\sigma^{2}}{S}>0,
\end{aligned}
$$


so

$$
\begin{aligned}
\frac{\hat{\sigma}_{\mathrm{L}}^{2}}{\hat{\sigma}_{\mathrm{J}}^{2}} & =\frac{\iota^{2}}{[\iota+(1-\iota) b]^{2}+b^{2}(S-1)} \in(0,1) \\
& \Rightarrow \frac{\partial\left(\hat{\sigma}_{\mathrm{L}}^{2} \hat{\sigma}_{\mathrm{J}}^{2}\right)}{\partial \iota}=2 \iota b \frac{(1-b) \iota+b S}{\left\{[\iota+(1-\iota) b]^{2}+b^{2}(S-1)\right\}^{2}}>0 \\
& \Rightarrow \frac{\partial\left(\hat{\sigma}_{\mathrm{L}}^{2} \hat{\sigma}_{\mathrm{J}}^{2}\right)}{\partial b}=-2 \iota^{2} \frac{(1-\iota)[\iota+(1-\iota) b]+b(S-1)}{\left\{[\iota+(1-\iota) b]^{2}+b^{2}(S-1)\right\}^{2}}<0 .
\end{aligned}
$$

\section{Proof of Corollary 2}

It is immediate from equation (A10) that

$$
\begin{aligned}
\operatorname{Var}\left(x_{t}^{\mathrm{J}} \mid x_{t-1}^{\mathrm{J}}\right) & =(1-\psi)^{2} \hat{\sigma}_{\mathrm{J}}^{2}>0, \\
\lim _{s \rightarrow \infty} \operatorname{Var}\left(x_{t+s}^{\mathrm{J}} \mid x_{t-1}^{\mathrm{J}}\right) & =\frac{1-\psi}{1+\psi} \hat{\sigma}_{J}^{2} .
\end{aligned}
$$

Naturally, $\operatorname{Var}\left(x_{t}^{\mathrm{L}} \mid x_{t}^{\mathrm{L}}\right)=0$, and proposition 4 proved that

$$
\lim _{s \rightarrow \infty} \operatorname{Var}\left(x_{t+s}^{\mathrm{L}} \mid x_{t}^{\mathrm{L}}\right)=\hat{\sigma}_{\mathrm{L}}^{2}
$$

so

$$
\lim _{s \rightarrow \infty} \operatorname{Var}\left(x_{t+s}^{\mathrm{L}} \mid x_{t}^{\mathrm{L}}\right)>\lim _{s \rightarrow \infty} \operatorname{Var}\left(x_{t+s}^{\mathrm{J}} \mid x_{t-1}^{\mathrm{J}}\right) \Leftrightarrow \psi>\frac{\hat{\sigma}_{\mathrm{J}}^{2}-\hat{\sigma}_{\mathrm{L}}^{2}}{\hat{\sigma}_{\mathrm{J}}^{2}+\hat{\sigma}_{\mathrm{L}}^{2}}
$$

From equation (A12) and proposition 4,

$$
\begin{aligned}
E\left[l\left(x_{t}^{\mathrm{J}}\right)\right] & =\frac{1-\psi}{1+\psi} \hat{\sigma}_{\mathrm{J}}^{2}+2 \frac{\psi^{2 t-1}}{1+\psi} \hat{\sigma}_{\mathrm{J}}^{2}, \\
E\left[l\left(x_{t}^{\mathrm{L}}\right)\right] & =\hat{\sigma}_{\mathrm{L}}^{2},
\end{aligned}
$$

so for all $\psi \in\left(\left(\hat{\sigma}_{\mathrm{J}}^{2}-\hat{\sigma}_{\mathrm{L}}^{2}\right) /\left(\hat{\sigma}_{\mathrm{J}}^{2}+\hat{\sigma}_{\mathrm{L}}^{2}\right), 1\right)$,

$$
\begin{gathered}
E\left[l\left(x_{t}^{\mathrm{L}}\right)\right] \geq E\left[l\left(x_{t}^{\mathrm{J}}\right)\right] \Leftrightarrow t \geq T \\
\equiv \frac{1}{2}\left\{\frac{\log \left[(1+\psi) \hat{\sigma}_{\mathrm{L}}^{2}-(1-\psi) \hat{\sigma}_{\mathrm{J}}^{2}\right]-\log \left(2 \hat{\sigma}_{\mathrm{J}}^{2}\right)}{\log \psi}+1\right\} .
\end{gathered}
$$


420 / THE JOURNAL OF LEGAL STUdiES / VOLUME 37 (2) / JUNE 2008

Proof of Proposition 6 and Corollary 3

The Evolution of Case Law. Given information $\Omega$, the expected flow loss under case law is

$$
\begin{aligned}
E\left[l\left(x_{t}^{\mathrm{J}}\right) \mid \Omega\right]= & {\left[E\left(x_{t}^{\mathrm{J}} \mid \Omega\right)-E\left(x_{t}^{*} \mid \Omega\right)\right]^{2}+\operatorname{Var}\left(x_{t}^{\mathrm{J}} \mid \Omega\right) } \\
& -2 \operatorname{Cov}\left(x_{t}^{\mathrm{J}}, x_{t}^{*} \mid \Omega\right)+\operatorname{Var}\left(x_{t}^{*} \mid \Omega\right),
\end{aligned}
$$

which includes two new sources of uncertainty: the exogenous variance of future optima and the inability of case law to adapt instantly to social change. The unconditional expectation is obtained when $\Omega=\left\{x_{1}^{*}\right\}$, a starting point whose value constitutes an irrelevant normalization.

The evolution of case law according to equation (A11) implies the moments

$$
\begin{aligned}
E\left(x_{t}^{\mathrm{J}} \mid x_{1}^{*}\right) & =\psi^{t} x_{1}^{*}+(1-\psi) \sum_{s=1}^{t} \psi^{t-s} E\left(x_{s}^{*} \mid x_{1}^{*}\right), \\
\operatorname{Var}\left(x_{t}^{\mathrm{J}} \mid x_{1}^{*}\right) & =\frac{1-\psi+2 \psi^{2 t-1}}{1+\psi} \hat{\sigma}_{\mathrm{J}}^{2}+(1-\psi)^{2} \sum_{s=2}^{t} \sum_{r=2}^{t} \psi^{2 t-s-r} \operatorname{Cov}\left(x_{s}^{*}, x_{r}^{*} \mid x_{1}^{*}\right), \\
\operatorname{Cov}\left(x_{t}^{\mathrm{J}}, x_{t}^{*} \mid x_{1}^{*}\right) & =(1-\psi) \sum_{s=2}^{t} \psi^{t-s} \operatorname{Cov}\left(x_{s}^{*}, x_{t}^{*} \mid x_{1}^{*}\right) .
\end{aligned}
$$

If we assume that $x_{t}^{*}$ is a martingale, for all $r \geq s>1$,

$$
\begin{aligned}
E\left(x_{s}^{*} \mid x_{1}^{*}\right) & =x_{1}^{*}, \\
\operatorname{Cov}\left(x_{s}^{*}, x_{r}^{*} \mid x_{1}^{*}\right) & =E\left[\left(x_{r}^{*}-x_{s}^{*}\right)\left(x_{s}^{*}-x_{1}^{*}\right) \mid x_{1}^{*}\right]+\operatorname{Var}\left(x_{s}^{*} \mid x_{1}^{*}\right) .
\end{aligned}
$$

In particular, when $x_{t}^{*}$ follows a jump process with hazard rate $\lambda$ and independent and identically distributed random increments $\xi$ such that $E(\xi)=0$ and $\operatorname{Var}(\xi)=\sigma_{\xi}^{2}$, then

$$
\operatorname{Cov}\left(x_{s}^{*}, x_{r}^{*} \mid x_{1}^{*}\right)=(\min \{r, s\}-1) \lambda \sigma_{\xi}^{2},
$$

and therefore the moments described in equation (A53) can be computed as

$$
\begin{gathered}
E\left(x_{t}^{\mathrm{J}} \mid x_{1}^{*}\right)=x_{1}^{*}, \\
\operatorname{Var}\left(x_{t}^{\mathrm{J}} \mid x_{1}^{*}\right)=\frac{1-\psi+2 \psi^{2 t-1}}{1+\psi} \hat{\sigma}_{\mathrm{J}}^{2}+(1-\psi)^{2} \lambda \sigma_{\xi}^{2} \sum_{s=2}^{t} \sum_{r=2}^{t}(\min \{r, s\}-1) \psi^{2 t-s-r}, \\
\operatorname{Cov}\left(x_{t}^{\mathrm{J}}, x_{t}^{*} \mid x_{1}^{*}\right)=(1-\psi) \lambda \sigma_{\xi}^{2} \sum_{s=2}^{t}(s-1) \psi^{t-s} .
\end{gathered}
$$


Hence, we can compute the ex ante expectation of the flow loss thus:

$$
E\left[l\left(x_{t}^{\mathrm{J}}\right)\right]=\frac{1-\psi}{1+\psi} \hat{\sigma}_{\mathrm{J}}^{2}+\frac{\psi^{2}}{1-\psi^{2}} \lambda \sigma_{\xi}^{2}+\frac{\psi^{2 t}}{1+\psi}\left(\frac{2 \hat{\sigma}_{\mathrm{J}}^{2}}{\psi}-\frac{\lambda \sigma_{\xi}^{2}}{1-\psi}\right) .
$$

The Evolution of the Mixed System. The ex ante expectation of the flow loss under the mixed system is

$$
E\left[l\left(x_{t}^{\mathrm{J}+\mathrm{L}}\right)\right]=\frac{1-\psi}{1+\psi} \hat{\sigma}_{\mathrm{J}}^{2}+E\left[\psi^{2 s_{t}}\right]\left(\hat{\sigma}_{\mathrm{L}}^{2}-\frac{1-\psi}{1+\psi} \hat{\sigma}_{\mathrm{J}}^{2}\right)
$$

where $x_{t}^{\mathrm{J}+\mathrm{L}}$ is the legal rule at time $t$ and $s_{t} \in[1, t]$ denotes the age of the most recently enacted statute.

For notational simplicity, we denote the probability that a statute is adopted in any period $t>1$ by

$$
\eta \equiv \lambda+(1-\lambda)(1-\alpha) \in[0,1] .
$$

The distribution of $s_{t}$ is characterized by the probability mass function

$$
P_{t}(s)= \begin{cases}\eta(1-\eta)^{s-1} & \text { if } s \in[1, t-1] \\ (1-\eta)^{s-1} & \text { if } s=t\end{cases}
$$

which implies

$$
E\left[\psi^{2 s_{t}}\right]=\frac{\eta \psi^{2}}{1-\psi^{2}+\eta \psi^{2}}+\frac{1-\psi^{2}}{1-\psi^{2}+\eta \psi^{2}}(1-\eta)^{t} \psi^{2 t},
$$

so the loss in equation (A57) can be computed as

$$
\begin{aligned}
E\left[l\left(x_{t}^{\mathrm{J}+\mathrm{L}}\right)\right]= & \frac{1-\psi^{2}}{1-\psi^{2}+\eta \psi^{2}} \frac{1-\psi}{1+\psi} \hat{\sigma}_{\mathrm{J}}^{2}+\frac{\eta \psi^{2}}{1-\psi^{2}+\eta \psi^{2}} \hat{\sigma}_{\mathrm{L}}^{2} \\
& +\frac{\left(1-\psi^{2}\right)(1-\eta)^{t} \psi^{2 t}}{1-\psi^{2}+\eta \psi^{2}}\left(\hat{\sigma}_{\mathrm{L}}^{2}-\frac{1-\psi}{1+\psi} \hat{\sigma}_{\mathrm{J}}^{2}\right) .
\end{aligned}
$$

Steady-State Efficiency. Aside from the short-run effects resulting from the origin of the system, the asymptotic losses for the three systems are stationary:

$$
\begin{aligned}
l_{\mathrm{L}} & =\hat{\sigma}_{\mathrm{L}}^{2}, \\
l_{\mathrm{J}} & =\frac{1-\psi}{1+\psi} \hat{\sigma}_{\mathrm{J}}^{2}+\frac{\psi^{2}}{1-\psi^{2}} \lambda \sigma_{\xi}^{2}, \\
l_{\mathrm{J}+\mathrm{L}} & =\frac{1-\psi^{2}}{1-\psi^{2}+\eta \psi^{2}} \frac{1-\psi}{1+\psi} \hat{\sigma}_{\mathrm{J}}^{2}+\frac{\eta \psi^{2}}{1-\psi^{2}+\eta \psi^{2}} \hat{\sigma}_{\mathrm{L}}^{2}
\end{aligned}
$$


422 / THE JOURNAL OF LEGAL STUdiES / VOLUME 37 (2) / JUNE 2008

The expected steady-state loss from case law is minimized by

$$
\psi_{\mathrm{J}}^{*}=\frac{2 \hat{\sigma}_{\mathrm{J}}^{2}+\lambda \sigma_{\xi}^{2}-\sqrt{\left(4 \hat{\sigma}_{\mathrm{J}}^{2}+\lambda \sigma_{\xi}^{2}\right) \lambda \sigma_{\xi}^{2}}}{2 \hat{\sigma}_{\mathrm{J}}^{2}},
$$

and comparative statics are obtained by the implicit-function theorem from the first-order condition

$$
\psi_{\mathrm{J}}^{* 2}-\left(2+\frac{\lambda \sigma_{\xi}^{2}}{\hat{\sigma}_{\mathrm{J}}^{2}}\right) \psi_{\mathrm{J}}^{*}+1=0
$$

The minimized loss equals

$$
l_{J}^{*}=\frac{\sqrt{\left(4 \hat{\sigma}_{J}^{2}+\lambda \sigma_{\xi}^{2}\right) \lambda \sigma_{\xi}^{2}}-\lambda \sigma_{\xi}^{2}}{2},
$$

which implies that

$$
l_{\mathrm{J}}^{*}>l_{\mathrm{L}} \Leftrightarrow \lambda \sigma_{\xi}^{2}>\frac{\hat{\sigma}_{\mathrm{L}}^{4}}{\hat{\sigma}_{\mathrm{J}}^{2}-\hat{\sigma}_{\mathrm{L}}^{2}}
$$

The expected steady-state loss from the mixed system is minimized by

$$
\psi_{\mathrm{J}+\mathrm{L}}^{*}= \begin{cases}\frac{(2-\eta) \hat{\sigma}_{\mathrm{J}}^{2}+\eta \hat{\sigma}_{\mathrm{L}}^{2}-\sqrt{\left[(2-\eta) \hat{\sigma}_{\mathrm{J}}^{2}+\eta \hat{\sigma}_{\mathrm{L}}^{2}\right]^{2}-4(1-\eta) \hat{\sigma}_{\mathrm{J}}^{4}}}{2(1-\eta) \hat{\sigma}_{\mathrm{J}}^{2}} & \text { if } \eta<1 \\ \frac{\hat{\sigma}_{\mathrm{J}}^{2}}{\hat{\sigma}_{\mathrm{J}}^{2}+\hat{\sigma}_{\mathrm{L}}^{2}} & \text { if } \eta=1,\end{cases}
$$

and comparative statics are obtained by the implicit-function theorem from the first-order condition

$$
(1-\eta) \psi_{\mathrm{J}+\mathrm{L}}^{* 2}-\left(2-\eta+\frac{\eta \hat{\sigma}_{\mathrm{L}}^{2}}{\hat{\sigma}_{\mathrm{J}}^{2}}\right) \psi_{\mathrm{J}+\mathrm{L}}^{*}+1=0
$$

if we recall that $1-\hat{\sigma}_{\mathrm{L}}^{2} / \hat{\sigma}_{\mathrm{J}}^{2}-\psi_{\mathrm{J}+\mathrm{L}}^{*}<0$.

The minimized loss equals

$$
l_{\mathrm{J}+\mathrm{L}}^{*}= \begin{cases}\frac{\sqrt{\eta^{2}\left(\hat{\sigma}_{\mathrm{J}}^{2}-\hat{\sigma}_{\mathrm{L}}^{2}\right)^{2}+4 \eta \hat{\sigma}_{\mathrm{J}}^{2} \hat{\sigma}_{\mathrm{L}}^{2}}-\eta\left(\hat{\sigma}_{\mathrm{J}}^{2}+\hat{\sigma}_{\mathrm{L}}^{2}\right)}{2(1-\eta)} & \text { if } \eta<1 \\ \frac{\hat{\sigma}_{\mathrm{J}}^{2} \hat{\sigma}_{\mathrm{L}}^{2}}{\hat{\sigma}_{\mathrm{J}}^{2}+\hat{\sigma}_{\mathrm{L}}^{2}} & \text { if } \eta=1,\end{cases}
$$

which immediately implies that $l_{\mathrm{L}}>l_{\mathrm{J}+\mathrm{L}}^{*}$ for all $\hat{\sigma}_{\mathrm{L}}^{2}>0$.

Finally, if we compare pure case law with the mixed system, the result is immediate for $\eta=1$. For $\eta<1$, it can be shown that

$$
l_{\mathrm{J}}^{*} \geq l_{\mathrm{J}+\mathrm{L}}^{*} \Leftrightarrow \lambda \sigma_{\xi}^{2} \geq \frac{\eta}{1-\eta}\left[\hat{\sigma}_{\mathrm{L}}^{2}-\frac{\sqrt{\eta^{2}\left(\hat{\sigma}_{\mathrm{J}}^{2}-\hat{\sigma}_{\mathrm{L}}^{2}\right)^{2}+4 \eta \hat{\sigma}_{\mathrm{J}}^{2} \hat{\sigma}_{\mathrm{L}}^{2}}-\eta\left(\hat{\sigma}_{\mathrm{J}}^{2}-\hat{\sigma}_{\mathrm{L}}^{2}\right)}{2}\right] .
$$


Thus, generally

$$
l_{\mathrm{J}}^{*} \geq l_{\mathrm{J}+\mathrm{L}}^{*} \Leftrightarrow \lambda \sigma_{\xi}^{2}>\rho\left(\hat{\sigma}_{\mathrm{J}}^{2}, \hat{\sigma}_{\mathrm{L}}^{2}, \eta\right),
$$

where

$$
\rho\left(\hat{\sigma}_{\mathrm{J}}^{2}, \hat{\sigma}_{\mathrm{L}}^{2}, \eta\right) \equiv \begin{cases}\frac{\eta}{1-\eta}\left[\hat{\sigma}_{\mathrm{L}}^{2}-\frac{\sqrt{\eta^{2}\left(\hat{\sigma}_{\mathrm{J}}^{2}-\hat{\sigma}_{\mathrm{L}}^{2}\right)^{2}+4 \eta \hat{\sigma}_{\mathrm{J}}^{2} \hat{\sigma}_{\mathrm{L}}^{2}}-\eta\left(\hat{\sigma}_{\mathrm{J}}^{2}-\hat{\sigma}_{\mathrm{L}}^{2}\right)}{2}\right] & \text { if } \eta<1 \\ \frac{\hat{\sigma}_{\mathrm{L}}^{4}}{\hat{\sigma}_{\mathrm{J}}^{2}+\hat{\sigma}_{\mathrm{L}}^{2}} & \text { if } \eta=1,\end{cases}
$$

so for all $\hat{\sigma}_{\mathrm{L}}^{2}>0$,

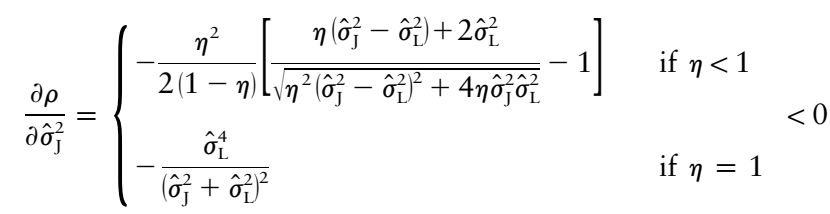

and

$$
\frac{\partial \rho}{\partial \hat{\sigma}_{\mathrm{L}}^{2}}= \begin{cases}\frac{\eta}{2(1-\eta)}\left[2-\eta-\eta \frac{(2-\eta) \hat{\sigma}_{\mathrm{J}}^{2}+\eta \hat{\sigma}_{\mathrm{L}}^{2}}{\sqrt{\eta^{2}\left(\hat{\sigma}_{\mathrm{J}}^{2}-\hat{\sigma}_{\mathrm{L}}^{2}\right)^{2}+4 \eta \hat{\sigma}_{\mathrm{J}}^{2} \hat{\sigma}_{\mathrm{L}}^{2}}}\right] & \text { if } \eta<1 \\ \frac{\left(\hat{\sigma}_{\mathrm{J}}^{2}+2 \hat{\sigma}_{\mathrm{L}}^{2} \hat{\sigma}_{\mathrm{L}}^{2}\right.}{\left(\hat{\sigma}_{\mathrm{J}}^{2}+\hat{\sigma}_{\mathrm{L}}^{2}\right)^{2}} & \text { if } \eta=1\end{cases}
$$

If we hold $\lambda$ constant, $\eta$ is determined by $\alpha$, and for all $\eta \in(0,1)$,

$$
\begin{aligned}
\frac{\partial \rho}{\partial \eta}= & \frac{1}{(1-\eta)^{2}}\left[\hat{\sigma}_{\mathrm{L}}^{2}-\frac{\sqrt{\eta^{2}\left(\hat{\sigma}_{\mathrm{J}}^{2}-\hat{\sigma}_{\mathrm{L}}^{2}\right)^{2}+4 \eta \hat{\sigma}_{\mathrm{J}}^{2} \hat{\sigma}_{\mathrm{L}}^{2}}-\eta\left(\hat{\sigma}_{\mathrm{J}}^{2}-\hat{\sigma}_{\mathrm{L}}^{2}\right)}{2}\right] \\
& +\frac{1}{2} \frac{\eta}{1-\eta}\left[\left(\hat{\sigma}_{\mathrm{J}}^{2}-\hat{\sigma}_{\mathrm{L}}^{2}\right)-\frac{\eta\left(\hat{\sigma}_{\mathrm{J}}^{2}-\hat{\sigma}_{\mathrm{L}}^{2}\right)^{2}+2 \hat{\sigma}_{\mathrm{J}}^{2} \hat{\sigma}_{\mathrm{L}}^{2}}{\sqrt{\eta^{2}\left(\hat{\sigma}_{\mathrm{J}}^{2}-\hat{\sigma}_{\mathrm{L}}^{2}\right)^{2}+4 \eta \hat{\sigma}_{\mathrm{J}}^{2} \hat{\sigma}_{\mathrm{L}}^{2}}}\right]>0
\end{aligned}
$$

establishes that $\partial \rho / \partial \alpha<0$.

Finally, we define

$$
\Xi\left(\hat{\sigma}_{\mathrm{J}}^{2}, \hat{\sigma}_{\mathrm{L}}^{2}, \alpha, \lambda\right) \equiv \frac{\rho\left(\hat{\sigma}_{\mathrm{J}}^{2}, \hat{\sigma}_{\mathrm{L}}^{2}, \lambda+(1-\lambda)(1-\alpha)\right)}{\lambda},
$$

so the optimality condition expressed in (A72) can be rewritten as

$$
l_{\mathrm{J}}^{*} \geq l_{\mathrm{J}+\mathrm{L}}^{*} \Leftrightarrow \sigma_{\xi}^{2} \geq \Xi\left(\hat{\sigma}_{\mathrm{J}}^{2}, \hat{\sigma}_{\mathrm{L}}^{2}, \alpha, \lambda\right),
$$


424 / THE JOURnal OF LEgal Studies / VOLUme 37 (2) / JUNE 2008

where equations (A74), (A75), and (A76) imply that $\partial \Xi / \partial \hat{\sigma}_{\mathrm{J}}^{2}<0, \partial \Xi / \partial \hat{\sigma}_{\mathrm{L}}^{2}>0$, and $\partial \Xi / \partial \alpha<0$, while

$$
\frac{\partial \Xi}{\partial \lambda}=\frac{1}{\lambda} \frac{\partial \rho}{\partial \eta} \frac{\partial \eta}{\partial \lambda}-\frac{1}{\lambda^{2}} \frac{\eta}{1-\eta}\left[\hat{\sigma}_{\mathrm{L}}^{2}+\frac{\eta\left(\hat{\sigma}_{\mathrm{J}}^{2}-\hat{\sigma}_{\mathrm{L}}^{2}\right)-\sqrt{\eta^{2}\left(\hat{\sigma}_{\mathrm{J}}^{2}-\hat{\sigma}_{\mathrm{L}}^{2}\right)^{2}+4 \eta \hat{\sigma}_{\mathrm{J}}^{2} \hat{\sigma}_{\mathrm{L}}^{2}}}{2}\right] .
$$

If we use equation (A76) and since $\partial \eta / \partial \lambda=(1-\eta) /(1-\lambda)$, equation (A78) implies that $\partial \Xi / \partial \lambda$ has the sign of

$$
\begin{aligned}
\Upsilon(\lambda, \eta) \equiv & \frac{\lambda}{1-\lambda}\left[2 \hat{\sigma}_{\mathrm{L}}^{2}-\sqrt{\eta^{2}\left(\hat{\sigma}_{\mathrm{J}}^{2}-\hat{\sigma}_{\mathrm{L}}^{2}\right)^{2}+4 \eta \hat{\sigma}_{\mathrm{J}}^{2} \hat{\sigma}_{\mathrm{L}}^{2}}+\eta(2-\eta)\left(\hat{\sigma}_{\mathrm{J}}^{2}-\hat{\sigma}_{\mathrm{L}}^{2}\right)\right. \\
& \left.+-\eta(1-\eta) \frac{\eta\left(\hat{\sigma}_{\mathrm{J}}^{2}-\hat{\sigma}_{\mathrm{L}}^{2}\right)^{2}+2 \hat{\sigma}_{\mathrm{J}}^{2} \hat{\sigma}_{\mathrm{L}}^{2}}{\sqrt{\eta^{2}\left(\hat{\sigma}_{\mathrm{J}}^{2}-\hat{\sigma}_{\mathrm{L}}^{2}\right)^{2}+4 \eta \hat{\sigma}_{\mathrm{J}}^{2} \hat{\sigma}_{\mathrm{L}}^{2}}}\right] \\
& +-\eta\left[2 \hat{\sigma}_{\mathrm{L}}^{2}+\eta\left(\hat{\sigma}_{\mathrm{J}}^{2}-\hat{\sigma}_{\mathrm{L}}^{2}\right)-\sqrt{\eta^{2}\left(\hat{\sigma}_{\mathrm{J}}^{2}-\hat{\sigma}_{\mathrm{L}}^{2}\right)^{2}+4 \eta \hat{\sigma}_{\mathrm{J}}^{2} \hat{\sigma}_{\mathrm{L}}^{2}}\right] .
\end{aligned}
$$

The function $\Upsilon(\lambda, \eta)$ is monotone increasing in $\lambda$, and $\Upsilon(\eta, \eta)$ is an increasing function of $\eta$; by l'Hôpital's rule, $\lim _{\eta \rightarrow 1} \Upsilon(\eta, \eta)=0$, so $\Upsilon(\lambda, \eta)<\Upsilon(\eta, \eta)<0$, which proves that $\partial \Xi / \partial \lambda<0$.

\section{Proof of Proposition 7}

Since a change in the social optimum determines the enactment of a new statute, at any point in time the law is a function of the age $s_{t} \in[1, t]$ of the most recently enacted statute $\hat{x}_{t+1-s_{t}}^{\mathrm{L}}$ with expectation $x^{*}$ and variance $\hat{\sigma}_{\mathrm{L}}^{2}>0$.

As in equation (A10), this implies conditional moments

$$
\begin{aligned}
E\left(x_{t}^{\mathrm{L}+\mathrm{J}} \mid s_{t}, \hat{x}_{t+1-s_{t}}^{\mathrm{L}}\right) & =x^{*}+\psi^{s_{t}}\left(\hat{x}_{t+1-s_{t}}^{\mathrm{L}}-x^{*}\right), \\
\operatorname{Var}\left(x_{t}^{\mathrm{L}+\mathrm{J}} \mid s_{t}, \hat{x}_{t+1-s_{t}}^{\mathrm{L}}\right) & =\left(1-\psi^{2 s_{t}}\right) \frac{1-\psi}{1+\psi} \hat{\sigma}_{\mathrm{J}}^{2},
\end{aligned}
$$

which generates inefficiency

$$
E\left[l\left(x_{t}^{\mathrm{L}+\mathrm{J}}\right) \mid s_{t}\right]=\frac{1-\psi}{1+\psi} \hat{\sigma}_{\mathrm{J}}^{2}+\psi^{2 s_{t}}\left(\hat{\sigma}_{\mathrm{L}}^{2}-\frac{1-\psi}{1+\psi} \hat{\sigma}_{\mathrm{J}}^{2}\right) .
$$

This implies that regardless of the process of social and political change, given a sufficient importance of precedent, the mixed system is preferable to pure statute law irrespective of accountability:

$$
\psi>\frac{\hat{\sigma}_{\mathrm{J}}^{2}-\hat{\sigma}_{\mathrm{L}}^{2}}{\hat{\sigma}_{\mathrm{J}}^{2}+\hat{\sigma}_{\mathrm{L}}^{2}} \Leftrightarrow E\left[l\left(x_{t}^{\mathrm{L}+\mathrm{J}}\right) \mid s_{t}\right]<E\left[l\left(x_{t}^{\mathrm{L}}\right)\right]=\hat{\sigma}_{\mathrm{L}}^{2} \quad \text { for all } t \text { and } s_{t} \in[1, t] .
$$

Moreover, $\partial E\left[l\left(x_{t}^{\mathrm{L}+\mathrm{J}}\right) \mid s_{t}\right] / \partial s_{t}<0$ implies that legislation in the absence of social 
change, which corresponds to an arbitrary reduction in $s_{t}$, is unambiguously detrimental, and therefore accountability is unambiguously beneficial.

\section{REFERENCES}

Bankowski, Zenon, Neil MacCormick, Lech Morawski, and Alfonso Ruiz Miguel. 1997. Rationales for Precedent. Pp. 481-502 in Interpreting Precedents: A Comparative Study, edited by Neil MacCormick and Robert S. Summers. Aldershot: Ashgate.

Beck, Thorsten, Asli Demirgüç-Kunt, and Ross Levine. 2003a. Law and Finance: Why Does Legal Origin Matter? Journal of Comparative Economics 31: 653-75.

- 2003b. Law, Endowments, and Finance. Journal of Financial Economics 70:137-81.

- 2005. Law and Firms' Access to Finance. American Law and Economic Review 7:211-52.

Bentham, Jeremy. 1998. "Legislator of the World": Writings on Codification, Law, and Education, edited by Philip Schofield and Jonathan Harris. New York: Oxford University Press.

Berkowitz, Daniel, Katharina Pistor, and Jean-François Richard. 2003. Economic Development, Legality, and the Transplant Effect. European Economic Review 47:165-95.

Brenner, Saul, and Harold Spaeth. 1995. Stare Indecisis: The Alteration of Precedent on the U.S. Supreme Court, 1946-1992. New York: Cambridge University Press.

Burke, Edmund. [1790] 1999. Reflections on the Revolution in France. Pp. 85-366 in vol. 2 of Select Works of Edmund Burke. Reprint, Indianapolis: Liberty Fund.

Butler, Henry N., and Larry E. Ribstein. 2006. The Sarbanes-Oxley Debacle: What We've Learned; How to Fix It. Washington, D.C.: AEI Press.

Calabresi, Guido. 1982. A Common Law for the Age of Statutes. Cambridge, Mass.: Harvard University Press.

Cardozo, Benjamin N. 1921. The Nature of the Judicial Process. New Haven, Conn.: Yale University Press.

- [1932] 1947. Jurisprudence. Pp. 7-46 in Selected Writings of Benjamin Nathan Cardozo. Reprint, New York: Fallon Publications.

Chandler, William B., and Leo E. Strine. 2003. The New Federalism of the American Corporate Governance System: Preliminary Reflections of Two Residents of One Small State. University of Pennsylvania Law Review 152: 953-1005.

Clark, Robert C. 2005. Corporate Governance Changes in the Wake of the 
426 / THE JOURNAL OF LEGAL STUdiES / VOLUME 37 (2) / JUNE 2008

Sarbanes-Oxley Act: A Morality Tale for Policymakers Too. Georgia State Law Review 22:251-312.

Coffee, John C., Jr. 2002. Convergence and Its Critics: What Are the Preconditions to the Separation of Ownership and Control? Pp. 83-112 in Corporate Governance Regimes: Convergence and Diversity, edited by Joseph McCahery, Luc Renneboog, Piet Moerland, and Theo Raaijmakers. Oxford: Oxford University Press.

Cooter, Robert, and Lewis Kornhauser. 1980. Can Litigation Improve the Law without the Help of Judges? Journal of Legal Studies 9:139-63.

Cooter, Robert, Lewis Kornhauser, and David Lane. 1979. Liability Rules, Limited Information, and the Role of Precedent. Bell Journal of Economics 10: 366-73.

Coudert, Frederic. 1913. Certainty and Justice: Studies of the Conflict between Precedent and Progress in the Development of the Law. New York: D. Appleton.

Dale, William. 1977. Legislative Drafting: A New Approach. London: Butterworth.

Damaska, Mirjan R. 1986. The Faces of Justice and State Authority. New Haven, Conn.: Yale University Press.

David, René, ed. 1973. International Encyclopedia of Comparative Law. New York: Oceana.

David, René, and John E. C. Brierley. 1985. Major Legal Systems in the World Today: An Introduction to the Comparative Study of Law. 3rd ed. London: Stevens.

David, René, and Henry P. de Vries. 1958. The French Legal System: An Introduction to Civil Law Systems. New York: Oceana.

Dawson, John P. 1968. The Oracles of the Law. Ann Arbor: University of Michigan Law School.

Debbasch, Charles, ed. 1986. L'inflation législative et réglementaire en Europe: Actes du colloque tenu a Aix en octobre 1985. Paris: Editions du CNRS.

Djankov, Simeon, Rafael La Porta, Florencio Lopez-de-Silanes, and Andrei Shleifer. 2003. Courts. Quarterly Journal of Economics 118:453-517.

- 2008. The Law and Economics of Self-Dealing. Journal of Financial Economics 88:430-65.

Djankov, Simeon, Caralee McLiesh, and Andrei Shleifer. 2007. Private Credit in 129 Countries. Journal of Financial Economics 84:299-329.

Döring, Herbert. 1995. Is Government Control of the Agenda Likely to Keep "Legislative Inflation" at Bay? Pp. 654-87 in Parliaments and Majority Rule in Western Europe, edited by Herbert Döring. New York: St. Martin's Press.

Douglas, William. 1980. The Court Years, 1939-1975: The Autobiography of William O. Douglas. New York: Random House.

Eng, Svein. 2002. Legislative Inflation and the Quality of Law. Pp. 65-80 in 
Legisprudence: A New Theoretical Approach to Legislation, edited by Luc J. Wintgens. Oxford: Hart.

Eskridge, William N., Philip P. Frickey, and Elizabeth Garrett. 2000. Legislation and Statutory Interpretation. New York: Foundation Press.

Frank, Jerome. 1930. Law and the Modern Mind. New York: Brentano's.

Gennaioli, Nicola. 2006. Contracting in the Shadow of the Law. Unpublished manuscript. Universitat Pompeu Fabra, Centre de Recerca en Economia Internacional (CREI), Barcelona.

Gennaioli, Nicola, and Andrei Shleifer. 2007. The Evolution of Common Law. Journal of Political Economy 115:43-68.

George, Tracey, and Lee Epstein. 1992. On the Nature of Supreme Court Decision Making. American Political Science Review 86:323-37.

Germain, Claire. 2003. Approaches to Statutory Interpretation and Legislative History in France. Duke Journal of Comparative and International Law 13: 195-206.

Gewirtz, Paul, and Chad Golder. 2005. So Who Are the Activists? New York Times, July 6.

Glaeser, Edward L., Giacomo A. M. Ponzetto, and Jesse M. Shapiro. 2005. Strategic Extremism: Why Republicans and Democrats Divide on Religious Values. Quarterly Journal of Economics 120:1283-1330.

Glaeser, Edward L., and Andrei Shleifer. 2002. Legal Origins. Quarterly Journal of Economics 117:1193-1229.

- 2003. The Rise of the Regulatory State. Journal of Economic Literature 41:401-25.

Glendon, Mary Ann. 1984. The Sources of Law in a Changing Legal Order. Creighton Law Review 663:665-84.

Glendon, Mary Ann, Michael W. Gordon, and Paolo G. Carozza. 1999. Comparative Legal Traditions in a Nutshell. St. Paul, Minn.: West Group.

Goodman, John. 1978. An Economic Theory of the Evolution of the Common Law. Journal of Legal Studies 7:393-406.

Grossman, Gene, and Elhanan Helpman. 1994. Protection for Sale. American Economic Review 84:833-50.

- 2001. Special Interest Politics. Cambridge, Mass.: MIT Press.

Hadfield, Gillian. 1992. Bias in the Evolution of Legal Rules. Georgetown Law Journal 80:583-616.

Hansford, Thomas, and James Spriggs. 2006. The Politics of Precedent on the U.S. Supreme Court. Princeton, N.J.: Princeton University Press.

Hathaway, Oona A. 2001. Path Dependence in the Law: The Course and Pattern of Legal Change in a Common Law System. Iowa Law Review 86:601-65.

Hayek, Friedrich A. 1973. Rules and Order. Vol. 1 of Law, Legislation, and Liberty. Chicago: University of Chicago Press.

Hertig, Gérard. 2004. Convergence of Substantive Law and Convergence of Enforcement: A Comparison. Pp. 328-47 in Convergence and Persistence in 
428 / THE JOURNAL OF LEGAL STUdiES / VOLUME 37 (2) / JUNE 2008

Corporate Governance, edited by Jeffrey Gordon and Mark Roe. Cambridge: Cambridge University Press.

Hobbes, Thomas. [1681] 2005. A Dialogue between a Philosopher and a Student of the Common Laws of England. Reprint, New York: Oxford University Press.

Holmes, Oliver Wendell, Jr. 1897. The Path of the Law. Harvard Law Review 10:457-78.

Hutchinson, Allan C. 2005. Evolution and the Common Law. New York: Cambridge University Press.

Jellum, Linda D., and David C. Hricik. 2006. Modern Statutory Interpretation. Durham, N.C.: Carolina Academic Press.

Kaplow, Louis. 1992. Rules versus Standards: An Economic Analysis. Duke Law Journal 42:557-629.

- 2000. General Characteristics of Rules. Pp. 502-28 in The Economics of Crime and Litigation. Vol. 5 of Encyclopedia of Law and Economics, edited by Boudewijn Bouckaert and Gerrit DeGeest. Cheltenham: Edward Elgar.

Klein, David. 2002. Making Law in the United States Courts of Appeals. Cambridge: Cambridge University Press.

Landau, David. 2005. The Two Discourses in Colombian Constitutional Jurisprudence: A New Approach to Modelling Judicial Behavior in Latin America. George Washington International Law Review 37:687-744.

Landes, William M., and Richard A. Posner. 1979. Adjudication as a Private Good. Journal of Legal Studies 8:235-84.

La Porta, Rafael, Florencio Lopez-de-Silanes, Cristian Pop-Eleches, and Andrei Shleifer. 2004. Judicial Checks and Balances. Journal of Political Economy 112:445-70.

La Porta, Rafael, Florencio Lopez-de-Silanes, and Andrei Shleifer. 2002. Government Ownership of Banks. Journal of Finance 57:265-301.

La Porta, Rafael, Florencio Lopez-de-Silanes, Andrei Shleifer, and Robert W. Vishny. 1997. Legal Determinants of External Finance. Journal of Finance 52:1131-50.

- 1998. Law and Finance. Journal of Political Economy 106:1113-55.

- 1999. The Quality of Government. Journal of Law, Economics, and Organization 15:222-79.

Lasser, Mitchel de S.-O.-l'E. 1995. Judicial (Self-) Portraits: Judicial Discourse in the French Legal System. Yale Law Journal 104:1325-1410.

Leoni, Bruno. 1961. Freedom and the Law. Princeton, N.J.: Van Nostrand.

Linarelli, John. 1996. Anglo-American Jurisprudence and Latin America. Fordham International Law Journal 20:50-89.

Llewellyn, Karl N. 1930a. The Bramble Bush: On Our Law and Its Study. New York: Oceana. 
. 1930b. A Realistic Jurisprudence: The Next Step. Columbia Law Review 30:431-65.

. 1960. The Common Law Tradition: Deciding Appeals. Boston: Little, Brown.

MacLean, Roberto G. 1982. Judicial Discretion in the Civil Law. Louisiana Law Review 43:45-56.

Mahoney, Paul G. 2001. The Common Law and Economic Growth: Hayek Might Be Right. Journal of Legal Studies 20:503-25.

Malleson, Kate. 1999. The New Judiciary: The Effects of Expansion and Activism. Aldershot: Ashgate.

McGuire, Kevin, and Michael MacKuen. 2005. Precedent and Preferences on the U.S. Supreme Court. Unpublished manuscript. University of North Carolina at Chapel Hill, Department of Political Science, Chapel Hill, N.C.

Merryman, John H. 1985. The Civil Law Tradition: An Introduction to the Legal Systems of Western Europe and Latin America. Stanford, Calif.: Stanford University Press.

- 1996. The French Deviation. American Journal of Comparative Law 44:109-19.

Mulligan, Casey B., and Andrei Shleifer. 2005. Conscription as Regulation. American Law and Economics Review 7:85-111.

Partridge, Anthony, and William Eldridge. 1974. The Second Circuit Sentencing Study: A Report to the Judges of the Second Circuit. Washington, D.C.: Federal Judicial Center.

Pinello, Daniel. 1999. Linking Party to Judicial Ideology in American Courts: A Meta-analysis. Justice System Journal 3:219-54.

Posner, Richard A. [1973] 2007. The Economic Analysis of Law. 7th ed. New York: Aspen Publishers.

- 1990. The Problems of Jurisprudence. Cambridge, Mass.: Harvard University Press.

- 1996. The Federal Courts: Challenge and Reform. Cambridge, Mass.: Harvard University Press.

—_. 2005a. Judicial Behavior and Performance: An Economic Approach. Florida State University Law Review 32:1259-79.

— 2005b. The Supreme Court 2004 Term: A Political Court. Harvard Law Review 119:31-102.

Pound, Roscoe. 1908. Common Law and Legislation. Harvard Law Review 21: 383-407.

- 1910. Law in Books and Law in Action. American Law Review 44: 12-36.

Priest, George. 1977. The Common Law Process and the Selection of Efficient Rules. Journal of Legal Studies 6:65-82.

Radin, Max. 1925. The Theory of Judicial Decisions: Or How Judges Think. American Bar Association Journal 11:357-62. 
430 / THE JOURNAL OF LEGAL STUdiES / VOLUME 37 (2) / JUNE 2008

Revesz, Richard. 1997. Environmental Regulation, Ideology, and the D.C. Circuit. Virginia Law Review 83:1717-72.

Rowland, C. K., and Robert Carp. 1996. Politics and Judgment in Federal District Courts. Lawrence: University Press of Kansas.

Rubin, Paul. 1977. Why Is the Common Law Efficient? Journal of Legal Studies 6:51-63.

Sáez, Felipe. 1998. The Nature of Judicial Reform in Latin America and Some Strategic Considerations. American University International Law Review 13: 1267-1325.

Scalia, Antonin. 1997. A Matter of Interpretation: Federal Courts and the Law. Princeton, N.J.: Princeton University Press.

Scheb, John M., and John M. Scheb II. 2002. Introduction to the American Legal System. Albany, N.Y.: West Legal Studies.

Segal, Jeffrey, and Harold Spaeth. 1996. The Influence of Stare Decisis on the Votes of the United States Supreme Court Justices. American Journal of Political Science 40:971-1003.

- 2002. The Supreme Court and the Attitudinal Model Revisited. New York: Cambridge University Press.

Shavell, Steven. 2006. The Appeal Process and Adjudicator Incentives. Journal of Legal Studies 35:1-29.

Sieder, Rachel, Line Schjolden, and Alan Angell. 2005. The Judicialization of Politics in Latin America. New York: Palgrave Macmillan.

Songer, Donald, and Stefanie Lindquist. 1996. Not the Whole Story: The Impact of Justices' Values on Supreme Court Decision Making. American Journal of Political Science 40:1049-63.

Stone, Julius. 1946. The Province and Function of Law. Sydney: Associated General Publications.

- 1959. The Ratio of the Ratio Decidendi. Modern Law Review 22: 597-620.

—. 1964. Legal Systems and Lawyers' Reasonings. Stanford, Calif.: Stanford University Press.

-1985. Precedent and the Law: Dynamics of Common Law Growth. Sydney: Butterworths.

Sunstein, Cass, David Schkade, and Lisa Michelle Ellman. 2004. Ideological Voting on Federal Courts of Appeals: A Preliminary Investigation. Stanford Law Review 90:301-54.

Troper, Michel, and Christophe Grzegorczyk. 1997. Precedent in France. Pp. 103-40 in Interpreting Precedents, edited by Neil MacCormick and Robert Summers. Aldershot: Ashgate.

Zweigert, Konrad, and Hein Kötz. 1998. Introduction to Comparative Law. 3rd ed. Oxford: Oxford University Press.

Zywicki, Todd. 2003. The Rise and Fall of Efficiency in the Common Law: A Supply-Side Analysis. Northwestern University Law Review 97:1551-1633. 